\title{
Barcelona como municipio turístico: algunos datos evolutivos y elementos de futuro*
}

\author{
Juan Antonio Duro \\ Universitat Rovira i Virgili. Departament d'Economia \\ juanantonio.duro@urv.cat
}

\section{David Rodríguez}

Pla Estratègic Metropolità de Barcelona

david.rodriguezb@gmail.com

Recepción: marzo de 2015

Aceptación: mayo de 2015

\section{Resumen}

Este trabajo analiza la evolución de Barcelona como municipio turístico en los últimos años atendiendo a diversos indicadores cuantitativos disponibles, tanto de demanda como de oferta. El manejo de estos ha permitido constatar el cambio experimentado por el turismo en la ciudad y su gran expansión. Esta expansión se ha materializado en términos de la demanda (en particular, pernoctaciones y estancia media) y de la oferta (plazas y su calidad y distribución territorial). Por otra parte, se subraya la progresiva internacionalización de la demanda (con pérdida de peso en el mercado nacional) y el avance hacia la diversificación de los mercados internacionales (con el crecimiento del mercado norteamericano). En todo caso, estos avances y progresos han generado algunas amenazas que se ciernen sobre la sostenibilidad de este crecimiento y que reclaman una política pública adecuada.

Palabras clave: Barcelona; crecimiento turístico; distribución territorial; alojamientos turísticos; turismo urbano.

\section{Resum. Barcelona com a municipi turistic: algunes dades evolutives $i$ elements de futur}

Aquest treball analitza l'evolució de Barcelona com a municipi turístic en els darrers anys atenent a diversos indicadors quantitatius disponibles, tant de demanda com d'oferta. La utilització d'aquests ha permès constatar el canvi experimentat pel turisme a la ciutat i la seva gran expansió. Aquesta expansió s'ha materialitzat en termes de la demanda (en particular, pernoctacions i estada mitjana) i de l'oferta (places i qualitat, i distribució territorial). D'altra banda, se subratlla la progressiva internacionalització de la demanda (amb pèrdua

* Los autores agradecen la inestimable ayuda de Josep Maria Prat en diversas partes del trabajo $y$, en especial, en lo que tiene que ver con la realización de los mapas incluidos en este. 
de pes en el mercat nacional) i l'avanç cap a la diversificació dels mercats internacionals (amb el creixement del mercat nord-americà). En tot cas, aquests avenços i progressos han generat algunes amenaces que planen sobre la sostenibilitat d'aquest creixement i que reclamen una política pública adequada.

Paraules clau: Barcelona; creixement turístic; distribució territorial; allotjaments turístics; turisme urbà.

Résumé. Barcelone en tant que ville touristique: certaines données de son évolution et des éléments futurs

Cet article analyse l'évolution de Barcelone en tant que ville touristique au cours des dernières années en fonction de différents indicateurs quantitatifs de l'offre et de la demande. L'utilisation de ces données révèle l'extraordinaire expansion de l'activité touristique et, donc, le changement subi par la ville. Cette expansion s'est concrétisée en termes de demande (y compris les nuitées et la durée moyenne de séjour) et l'offre (quantité et qualité, et distribution territoriale). Par ailleurs, l'internationalisation progressive de la demande (avec la réduction des touristes espagnols) et la diversification des marchés internationaux (avec la croissance des États-Unis) est soulignée. Dans tous les cas, ces développements ont généré certaines menaces pour la durabilité de cette croissance. Par conséquent, il est très nécessaire de formuler une politique publique adéquate.

Mots-clés: Barcelone; croissance du tourisme; distribution territoriale; établissements touristiques; tourisme urbain.

\section{Abstract. Barcelona as a tourist city: Some insights into recent and future trends}

This paper analyses the recent conversion of Barcelona into a tourist city using a variety of quantitative indicators from both the demand and the supply side. These indicators reveal the enormous growth of tourism activity in Barcelona and how this trend has transformed the city. Tourism expansion has materialized in terms of demand (including overnight and average stays) and supply (number and quality of beds, spatial distribution). Moreover, the gradual relative growth of international demand and the diversification of international origins (especially in relation with the US market) are emphasized. Such changes pose some threats to the future of the Barcelona tourism model, which require an adequate public policy response.

Keywords: Barcelona; tourist growth; spatial distribution; tourist establishments; urban tourism.

\section{Sumario}

\section{Introducción}

2. Barcelona en el contexto turístico mundial

3. La evolución del turismo en Barcelona

4. El perfil del turista que viene a Barcelona
5. Oferta de alojamientos turísticos en Barcelona y su ubicación

6. Elementos de futuro

7. Conclusiones y consideraciones finales

Referencias bibliográficas 


\section{Introducción}

El turismo se ha convertido en un fenómeno de masas global. Lo que era un consumo de tipo superior (esto es, de alta elasticidad-renta de la demanda) se ha convertido prácticamente en un bien básico, al menos en lo que respecta a la propia decisión de viajar. Se ha incrementado el volumen de turistas, en todas las edades, el número de viajes, los destinos, etc. Las mayores disponibilidades de ocio, el crecimiento de la renta y la educación o las mejoras en las infraestructuras y equipamientos de transporte, fundamentalmente aéreo, se encuentran entre los principales desencadenantes de este escenario, por otra parte siempre cambiante (Buhalis, 2000; Pearce, 2001).

En este contexto, desde los Juegos Olímpicos de 1992, Barcelona constituye un destino turístico de talla mundial (Garay y Cànoves, 2009). La ciudad cambió, se renovó (incluso urbanísticamente), adoptó una estrategia de apertura al mundo, construyó y, en definitiva, se puso en el mapa mundial. Hoy es una ciudad global, con un montante de viajeros recibidos ciertamente elevado, a la que la crisis económica interna ha afectado en menor medida y con gran proyección de futuro (Ashworth, y Page, 2011). Efectivamente, la última crisis económica, global, también ha afectado a las ciudades, con una disminución de sus ingresos, un mayor endeudamiento, un retraso en los pagos a proveedores, un aumento del paro y una reducción de los niveles de consumo de su población. Por ello, en el marco de la actual situación económica y de la creciente competitividad entre las ciudades, la política urbana se ha caracterizado en estos últimos años por una progresiva orientación hacia la captación de nuevos flujos de capital, poniendo en valor turístico sus principales elementos diferenciadores, como herramienta de atracción de la ciudad (Buhalis, 2000; Nel.lo, 2012).

Sin embargo, Barcelona es una ciudad cuyo éxito turístico genera nuevos interrogantes respecto a su crecimiento sostenible futuro. Así, el propio desarrollo del destino ha entrañado un flujo de externalidades negativas (Judd, 2003) que se han hecho sentir, especialmente, en el verano de 2014. También la crisis está cambiando los hábitos de los consumidores, que cada vez buscan más el binomio precio-calidad en la oferta turística (Richards y Palmer, 2010).

Ahora bien, no es objeto de este trabajo realizar una discusión académica sobre los costes y beneficios de este desarrollo sino describir la posición y evolución de Barcelona a partir de los datos disponibles y analizar su distribución territorial. La batería de indicadores oficiales sobre turismo es suficientemente amplia como para tener una perspectiva bastante completa de lo acaecido en este municipio. En este sentido, la información, por ejemplo, cubre tanto la demanda como la oferta, aunque en todo caso se encuentra restringida por la disponible. Los datos, tomados de diferentes fuentes (aunque fundamen-

1. A finales de verano del año 2014, en la prensa, como por ejemplo en la edición de El País para Cataluña, aparecieron algunos artículos haciéndose eco de las movilizaciones de algunas asociaciones de vecinos y movimientos de ciudadanos para reducir la cifra de visitantes que recibía Barcelona y así minimizar los impactos negativos que estos provocaban en la ciudad y en sus residentes (http://ccaa.elpais.com/ccaa/2014/09/20/catalunya/1411240210_809038.html). 
talmente de Turisme de Barcelona, la agencia local de promoción), permite conocer algunas de las principales peculiaridades de este destino. En particular, el análisis va a cubrir los indicadores de demanda y su detalle en términos de perfil y evolución mensual, y los indicadores de la oferta en los diferentes distritos en que se divide la ciudad.

En este artículo no solo se va a realizar un análisis descriptivo de la evolución del turismo en la ciudad de Barcelona en estas últimas décadas, el perfil del turista que la visita y la distribución espacial de la oferta, sino que también se apuntan algunos elementos estratégicos de futuro, asociados con las amenazas que se perciben y que pueden constituir un obstáculo para el desarrollo futuro del destino. El trabajo se organiza de la forma siguiente. En el apartado segundo se revisa la posición de Barcelona en el contexto turístico mundial. En el apartado tercero se examina su evolución reciente atendiendo a la dinámica trazada por los indicadores de demanda y en la sección cuarta se detalla el perfil del turista que recibe Barcelona. En la quinta se analiza la evolución de la oferta de alojamientos turísticos de la ciudad y su distribución espacial. El punto sexto aborda algunos elementos estratégicos de futuro a partir de los datos examinados en los apartados anteriores. Finalmente, se dedica un apartado a recoger las principales conclusiones obtenidas en este trabajo y otro a listar la bibliografía referenciada.

\section{Barcelona en el contexto turístico mundial}

En el modelo económico vigente, las administraciones públicas realizan grandes inversiones en infraestructuras de transporte y telecomunicaciones (Benach y Tello, 2004; Capel, 2010), y abordan grandes proyectos urbanos, como la renovación de barrios enteros o la organización de eventos internacionales (Buhalis, 2000; Ponce, 2007; Borja, 2010; Capel, 2010; Nel.lo, 2012). Esta reconversión urbana no está exenta de dificultades, ya que, además del consiguiente endeudamiento público, los gestores tienen que decidir dónde intervenir, cómo y cuándo hacerlo, cómo controlar los efectos económicos perseguidos y evitar la conflictividad social (Benach, 1993). Todo ello ha hecho que el turismo urbano haya emergido con fuerza en estos últimos años como un elemento con identidad propia (Richards y Palmer, 2010) y que desde el sector público se haya apoyado, cada vez más decididamente, a la iniciativa privada, que se ha convertido en la principal beneficiaria de esta reestructuración urbana (Benach y Tello, 2004; Garay y Cànoves, 2009; Borja, 2010).

La llegada masiva de turistas ha servido para que las grandes ciudades, que suelen acumular gran cantidad de patrimonio urbano con valor turístico potencial (Judd, 2003; Toselli, 2006; Velasco, 2009; Prat, 2012), dependan cada vez más de los espacios comerciales, culturales, de ocio y recreación, de servicios y equipamientos, y busquen su diferenciación de marca como principal elemento de atracción y competitividad internacional (Dachevsky, 2001; Barrado, 2010).

Además, las expectativas condicionan la posición de las ciudades como destino turístico, dentro de los procesos de selección y satisfacción del turista, 
Tabla 1. Ranking de principales ciudades europeas por número de turistas (2012)

\begin{tabular}{clccc}
\hline $\begin{array}{c}\text { Posición } \\
\text { ranking europeo }\end{array}$ & Ciudad & $\begin{array}{c}\text { Posición ranking } \\
\text { mundial }\end{array}$ & $\begin{array}{c}\text { Posición ranking } \\
\text { europeo 2006 }\end{array}$ & $\begin{array}{c}\text { Visitantes extranjeros } \\
\text { (en miles) }\end{array}$ \\
\hline 1 & Londres & 4 & 1 & $15.461,0$ \\
2 & París & 10 & 2 & $9.780,8$ \\
3 & Estambul & 11 & 6 & $8.820,1$ \\
4 & Roma & 12 & 3 & $8.670,7$ \\
5 & Praga & 19 & 9 & $6.547,7$ \\
6 & Barcelona & 23 & 4 & $5.459,1$ \\
7 & Moscú & 24 & 10 & $5.036,2$ \\
8 & Budapest & 27 & 17 & $4.821,6$ \\
9 & Viena & 28 & 11 & $4.328,7$ \\
10 & Ámsterdam & 29 & 8 & $4.289,2$ \\
\hline
\end{tabular}

Fuente: elaboración propia a partir de datos de Euromonitor International (2014).

y por tanto su gestión es un aspecto crítico para los responsables del turismo urbano (González y Morales, 2009; Smith, 2012). En consecuencia, al diseñar la promoción de una ciudad, los gestores han de tener muy en cuenta cuáles son los factores que ayudarán a la satisfacción de los turistas durante todas sus experiencias a lo largo del viaje (Richards y Palmer, 2010). Con ello se favorecerá la imagen de la ciudad y los turistas construirán unas expectativas positivas que les permitan repetir la visita en un futuro o promocionar la ciudad entre potenciales visitantes (Judd, 2003; Stanciulescu, 2009).

Barcelona no ha sido ajena a este fenómeno y la actividad turística conforma en gran medida la estructura económica de la capital catalana (Bové y Guim, 2013). En efecto, y a pesar de su fortaleza competitiva en ámbitos sectoriales como la logística y los servicios avanzados, sus recursos competitivos en el ámbito turístico han provocado un aumento de peso de estas actividades en la generación de producto a escala local y de ocupación. Específicamente, y según estimaciones de Insetur (Universitat de Girona), el peso actual del PIB turístico en la economía de Barcelona alcanzaría el 12\%, esto es, unos 14.000 millones de euros.

En particular, Barcelona se situaría en posiciones a escala mundial e internacional ciertamente elevadas (y la primera en España) de visitantes recibidos. Con un volumen estimado de casi cinco millones y medio de visitantes extranjeros en 2012, se sitúa como el vigésimo tercero destino mundial por número de turistas recibidos, al mismo nivel que ciudades como Las Vegas, Miami o Pekín. En relación con Europa, se ubica en la sexta posición, inmediatamente tras Praga y por delante de Moscú (Tabla 1). En todo caso, los cambios en la clasificación, comparándola con la del año 2006, ilustran el grado de dinámica de este fenómeno. Así, por ejemplo, Praga o Budapest han ganado más de tres posiciones en esta clasificación, mientras que Barcelona ha perdido dos.

En términos de gasto turístico, un indicador de demanda monetario y no de tipo poblacional como el anterior, Barcelona se situó en 2014 en el séptimo 
Tabla 2. Ranking de principales ciudades mundiales por gasto turístico (2014)

\begin{tabular}{rrr}
\hline Posición & Ciudad & $\begin{array}{c}\text { Gasto turistas extranjeros } \\
\text { (en mill. \$ USA) }\end{array}$ \\
\hline 1 & Londres & 19.270 \\
2 & Nueva York & 18.570 \\
3 & París & 17.020 \\
4 & Singapur & 14.340 \\
5 & Bangkok & 13.040 \\
6 & Seúl & 11.510 \\
7 & Barcelona & 11.250 \\
8 & Dubái & 10.950 \\
9 & Taipéi & 10.810 \\
10 & Estambul & 9.380 \\
\hline
\end{tabular}

Fuente: elaboración propia a partir de datos de MasterCard (Hedrick-Wong y Choong, 2014).

Tabla 3. Clasificación de ciudades, Índice IGPC 2014 (Global Power City Index)

\begin{tabular}{lcc}
\hline \multicolumn{1}{c}{ Ciudad } & Posición según la percepción del visitante & Posición global \\
\hline Londres & 1 & 1 \\
Nueva York & 2 & 2 \\
París & 3 & 3 \\
Estambul & 4 & 21 \\
Shanghái & 5 & 15 \\
Tokio & 6 & 4 \\
Pekín & 7 & 14 \\
Barcelona & 8 & 27 \\
Singapur & 9 & 5 \\
Berlín & 10 & 8 \\
\hline
\end{tabular}

Fuente: elaboración propia a partir de datos del IGPC 2014 (Institute for Urban Strategies, Mori Foundation, 2014).

lugar de la clasificación mundial (y tercera europea), con un importe estimado de 11.250 millones de dólares estadounidenses, según datos de MasterCard (Hedrick-Wong y Choong, 2014). Este hecho la sitúa por delante de destinos como Dubai o Estambul y justo por detrás de ciudades globales como son Londres, Nueva York o Singapur (Tabla 2).

Barcelona también se ha consolidado, además, como uno de los principales puertos mundiales de cruceros turísticos al ampliar sus terminales y su capacidad de amarre de grandes cruceros (PAB, 1989). En 2013 fue el cuarto puerto mundial y el primero en el ámbito europeo por número de cruceristas, con casi 2,6 millones de pasajeros, inmediatamente detrás de los tres puertos base de las principales compañías del sector (Carnival y Royal Caribbean) en Florida (Hosteltur, 2014).

Finalmente, otro dato que confirma la atracción turística de Barcelona es su ubicación en el ranking de ciudades globales, elaborado anualmente por el Institute for Urban Strategies, Mori Foundation (2014), y considerado una 
referencia en la comparación de metrópolis. Barcelona, una ciudad que globalmente se ubicaría en un segundo nivel en términos globales ( $27^{a}$ posición en 2014), se convierte en una ciudad puntera, comparable a los grandes centros mundiales por lo que respecta a su actividad turística. En el último ranking disponible, correspondiente a 2014, se sitúa en octava posición por lo que respecta a la percepción del visitante, por delante de ciudades como Singapur o Berlín, e inmediatamente después de Tokio y Pekín (Tabla 3).

\section{La evolución del turismo en Barcelona}

La privilegiada situación de Barcelona en el mercado del turismo mundial ha sido posible, en parte, gracias a tres décadas de crecimiento planificado (Garay y Cànoves, 2009). A principios de los años ochenta, Barcelona era una ciudad dedicada eminentemente a la industria, a la que se vinculaba un fuerte sector comercial. No obstante, los cambios económicos posteriores, tanto en el ámbito europeo como mundial, apuntaron a un cambio de paradigma que irreversiblemente dependió de la pérdida de peso del sector industrial, tanto en valores absolutos como relativos, y que tuvo que compensarse con otras actividades vinculadas al sector servicios. Ello permitió a Barcelona no solo suplir la actividad industrial sino también ser una ciudad competitiva con la vista puesta en el siglo XXI. Al mismo tiempo se produjo una transferencia de actividades industriales hacia las coronas metropolitanas en busca de factores de competitividad diferenciales relacionados con la disponibilidad de suelo y precio, ubicación o dotación infraestructural. Fruto de este proceso, se detectaron una serie de actividades con potencial de crecimiento. Una de ellas era el turismo urbano.

La situación de partida era la de una ciudad en la que el turismo ejercía un papel menor, cuando no marginal, en el conjunto de actividades económicas ${ }^{2}$. Este se concebía eminentemente como un turismo de negocios, y el turismo recreacional era secundario y en muchos casos complementario al turismo de sol y playa de destinos costeros cercanos (como la Costa Brava o la Costa Dorada). A esta situación se le unía una oferta hotelera insuficiente, unas infraestructuras de acceso inadecuadas y una insuficiente política de promoción turística integrada (Turisme de Barcelona, 1995).

Ante esta situación, el Ayuntamiento de Barcelona abanderó el cambio de modelo ${ }^{3}$, que se concretó en:

— un ambicioso plan de crecimiento de la oferta hotelera, centrada en un aumento de la capacidad en las categorías superiores,

2. Véase López Palomeque (1995) para un análisis de la situación de la ciudad como destino turístico previa a los Juegos Olímpicos de 1992.

3. El Ayuntamiento de Barcelona, sensible a la nueva realidad, incluyó un Plan Estratégico de Turismo de la Ciudad de Barcelona, mediante un conjunto de objetivos y líneas de actuación para el desarrollo del turismo en la capital barcelonesa, dentro del Programa de Actuación Municipal (PAM) elaborado para el período 2008-2011 y aprobado a 31 de octubre de 2008 (Ajuntament de Barcelona, 2009; Turisme de Barcelona, 2015b). 
- la creación de infraestructuras culturales de primer nivel que permitieran una oferta cultural adecuada a la ciudad,

- la creación de una entidad público-privada de promoción turística,

- la reconversión de antiguas zonas industriales en nuevas zonas urbanas, el saneamiento de la zona marítima, la adecuación de nuevas playas, la mejora de la conectividad interna (los «cinturones de ronda») y la ampliación del aeropuerto.

Obviamente, los resultados finales han dependido de los factores de impulso ligados a la política y también de la coincidencia, asimismo, con otros factores de demanda que han favorecido el crecimiento (Bové y Guim, 2013). Entre estos podrían citarse, entre otros, la coyuntura global expansiva de la demanda asociada al carácter de bien básico atribuido al turismo; la mejora de las infraestructuras viarias y equipamientos, en especial ligadas a aeropuertos y empresas de transporte aéreo; o el aumento de la renta global en el último período, a excepción hecha, lógicamente, de los últimos años.

Tras la consolidación de estos nuevos factores, los resultados obtenidos han sido, en todo caso, elocuentes. Por lo que respecta al número de visitantes, en 1990, dos años antes de la celebración de los Juegos Olímpicos, estos ascendieron a 1,8 millones, de los que aproximadamente el $80 \%$ lo hicieron por motivos profesionales. Sin embargo, a partir de entonces el cambio fue sustancial (Vila, 1992; Duran, 2002).

Tras los Juegos Olímpicos de 1992 (Gráfico 1), el número de visitantes aumentó y en 2013 se situó en 7,5 millones, más de la mitad de los cuales fueron visitantes vacacionales, según los datos ofrecidos por Turisme de Barcelona (2015a). El crecimiento ha sido sostenido a lo largo de este periodo (19932013), con una ligera salvedad en 2000-2001, años en que se produjo una crisis económica global. Posteriormente, se experimentó una nueva aceleración en el

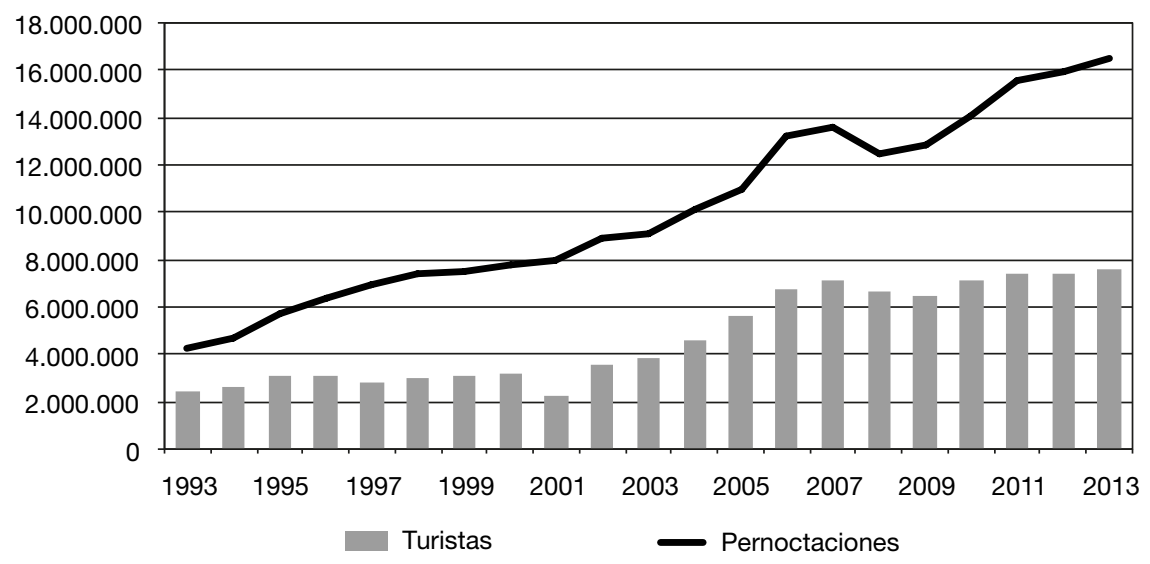

Gráfico 1. Evolución de la actividad turística en Barcelona (1993-2013).

Fuente: elaboración propia a partir de datos de Turisme de Barcelona (2015a). 


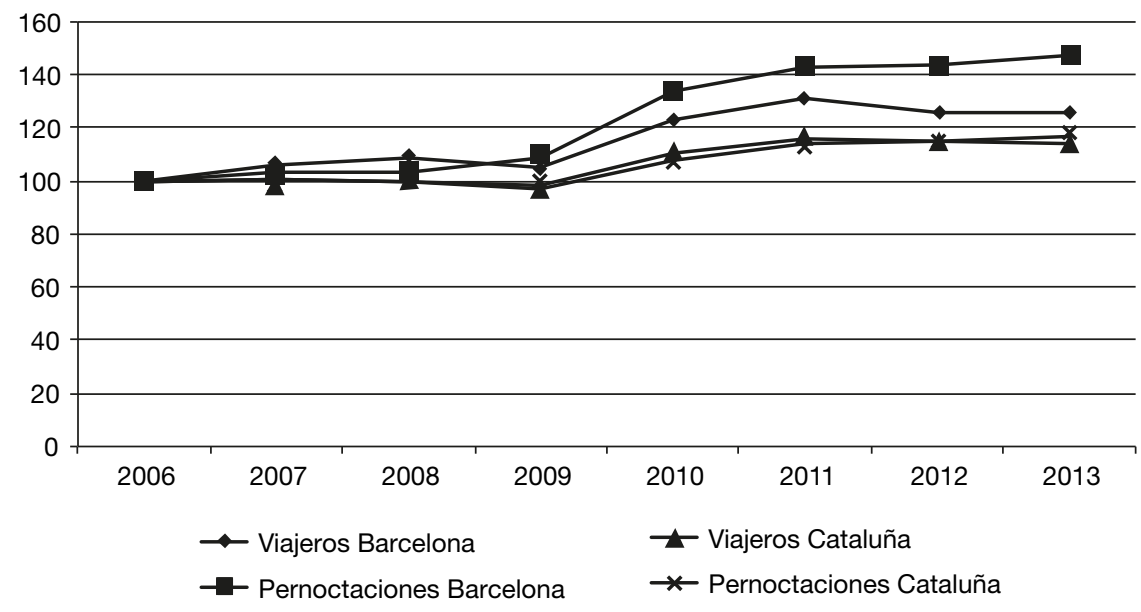

Gráfico 2. Evolución de la demanda hotelera en Barcelona y Cataluña (2006-2013).

Fuente: elaboración propia a partir de datos de la Encuesta de Ocupación Hotelera (INE).

periodo 2002-2007. Asimismo, las pernoctaciones de estos turistas han pasado de 4,256 millones en 1993 a 16,485 millones en 2013, lo que representa un crecimiento del $287,29 \%$. El crecimiento de las pernoctaciones ha sido más sostenido a lo largo de todo el periodo, excepto en el inicio de la última crisis (2008), aunque ha vuelto a repuntar un par de años después.

A partir de los datos procedentes de la Encuesta de Ocupación Hotelera ${ }^{4}$ del Instituto Nacional de Estadística (INE), se ha analizado la serie temporal de viajeros y pernoctaciones en establecimientos hoteleros de Barcelona en comparación con Cataluña (Gráfico 2). Se puede observar, por ejemplo, el ascenso desde 2009 (año de gran crisis global en los indicadores de demanda), especialmente en las pernoctaciones en la ciudad. La variación de los viajeros en los establecimientos hoteleros de Barcelona alcanza un 19\% y un 31\% en el caso de las pernoctaciones asociadas, cifras que son superiores a los totales catalanes ( $15 \%$ y $21 \%$ respectivamente).

Como consecuencia de la evolución más positiva de las pernoctaciones en relación con los viajeros, la estancia media ha progresado de las 2,06 noches en 2008 a las 2,53 de 2013. La estancia media ha crecido un $23 \%$ en este periodo, patrón claramente más expansivo que el registrado en toda Cataluña (4,2\% en el mismo período). En consecuencia, la demanda crece por una combinación positiva de mayor llegada de turistas y de mayor estancia media. Similar observación puede hacerse de la demanda turística en determinadas instalaciones. Así,

4. La Encuesta de Ocupación Hotelera ofrece las cifras oficiales españolas, que permiten comparaciones territoriales homogéneas. Se ha analizado la información a partir del año 2006, en que se produjo un cambio metodológico en la obtención de los datos. 
Tabla 4. Visitantes a las principales atracciones turísticas en Barcelona (1990-2013)

\begin{tabular}{lrrrrrr}
\hline \multicolumn{1}{c}{ Atracción } & \multicolumn{1}{c}{1990} & \multicolumn{1}{c}{1995} & 2000 & \multicolumn{1}{c}{2005} & 2010 & \multicolumn{1}{c}{2013} \\
\hline Sagrada Família & 701.713 & 728.191 & 1.420 .870 & 2.376 .780 & 2.317 .349 & 3.176 .970 \\
Museo FCB & 286.584 & 609.835 & 1.156 .090 & 1.133 .733 & 1.311 .638 & 1.506 .022 \\
Museo Picasso & 628.664 & 778.982 & 1.026 .549 & 1.074 .060 & 1.065 .388 & 915.226 \\
La Pedrera & $\mathrm{n} / \mathrm{d}$ & $\mathrm{n} / \mathrm{d}$ & 1.376 .721 & 1.261 .462 & 973.603 & 944.509 \\
MNAC & $\mathrm{n} / \mathrm{d}$ & $\mathrm{n} / \mathrm{d}$ & 368.063 & 769.914 & 897.179 & 635.917 \\
Poble Espanyol & $\mathrm{n} / \mathrm{d}$ & 1.347 .310 & 1.478 .543 & 1.305 .557 & 936.455 & 1.258 .645 \\
\hline
\end{tabular}

Nota: El MNAC se inauguró en 1996 y La Pedrera se abrió al público en su formato actual en 1999.

Fuente: elaboración propia a partir de datos de Turisme de Barcelona (2015a).

el Bus Turístico, implantado en 1987, vio cuadruplicar su demanda entre 1995 y 2005, hasta situarse en 2 millones de pasajeros anuales, al mismo tiempo que irrumpían otros operadores privados alternativos. El mismo fenómeno puede observarse en atracciones emblemáticas como la Sagrada Família o el Museo del FC Barcelona (FCB), que han visto multiplicar el número de visitas. O incluso en los últimos años se han incorporado nuevos espacios en el circuito con un éxito notable, como La Pedrera o la Casa Batlló (Tabla 4). En el caso de esta última, la cifra de visitantes ronda ya los 800.000 , cuando una década atrás ni tan siquiera se había considerado su apertura al público.

Finalmente, también ha sido importante la evolución del turismo de cruceros en la ciudad en las últimas dos décadas (Cànoves y Garay, 2012). Fue otra apuesta estratégica realizada en los años ochenta (en este caso por la Autoridad Portuaria). Se concretó tanto en una política activa de captación de companías navieras, como en la ampliación del puerto, sus terminales y estructuras logísticas. Gracias a ello, el crecimiento de esta actividad ha sido especialmente intenso en la última década, muy superior al crecimiento del sector turístico. El número de cruceristas se multiplicó por cinco entre 2000 y 2010 hasta situarse en cerca de 2,5 millones de pasajeros.

\section{El perfil del turista que viene a Barcelona}

La formación de la imagen de marca de las ciudades depende de diversos factores. Uno de ellos lo constituyen los rasgos sociodemográficos de los turistas que las visitan (género, edad, estado civil, grado de formación, nivel económico, lugar de origen, etc.), sus valores culturales y sus motivaciones. Por ello es necesario conocer con la mayor exactitud posible no solamente el perfil de este colectivo, teniendo en cuenta su dinamismo cambiante, sino también la imagen que tiene el destino para cada uno de los públicos objetivos (Mittal y Kamakura, 2001; Parker y Matthews, 2001).

Ante esta situación, uno de los principales objetivos en la creación de Turisme de Barcelona, esto es, la agencia local de promoción, fue la generación de datos relativos a la demanda turística que permitieran la toma de decisiones, 


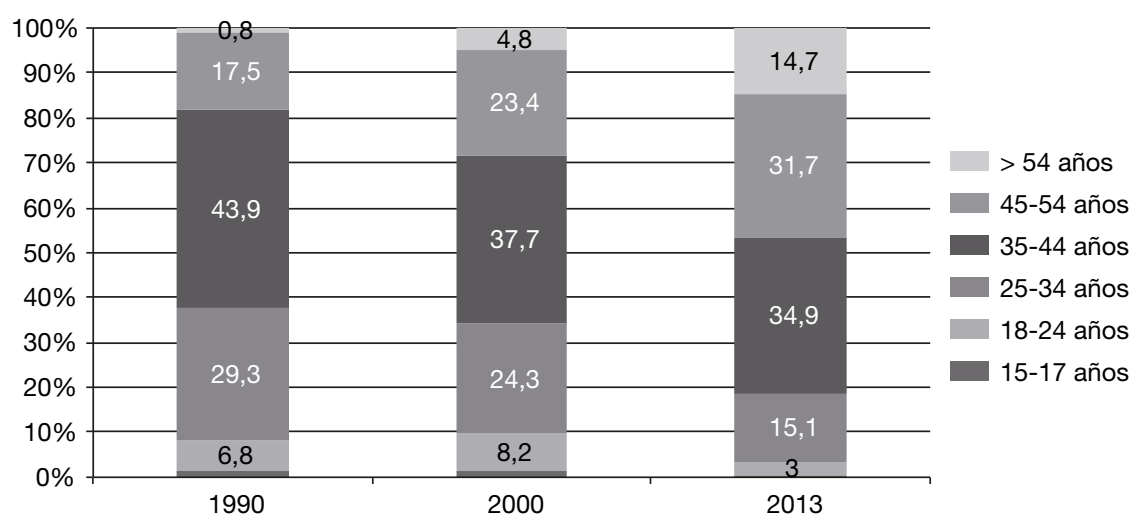

Gráfico 3. Edad de los visitantes en Barcelona.

Fuente: elaboración propia a partir de datos de Turisme de Barcelona (2015a).

tanto desde un punto de vista estratégico general como de comercialización. Hasta entonces los datos existentes eran muy escasos e inconexos entre ellos. Gracias a ello, se cuenta con una serie histórica desde 1993, que ha ido ampliándose con el paso del tiempo. No obstante, al tratarse de series estadísticas que no forman parte del sistema oficial, presentan algunas limitaciones técnicas, especialmente en lo concerniente a la metodología, las rupturas de series y la comparabilidad geográfica. Al interpretar los datos debe tenerse en cuenta esta limitación, sin que ello invalide el conjunto de las estadísticas. En todo caso, y para mejorar la comparabilidad, se han utilizado también fuentes globales.

El turista barcelonés es mayoritariamente masculino, el 58\% en 2013. Es una proporción relativamente estable a lo largo de los últimos años y coherente con el peso aún importante del turismo de negocios, en especial el relacionado con ferias y convenciones. No hay que olvidar que en dicho año se realizaron 291 congresos y 1.748 convenciones en la capital catalana (Ayuntamiento de Barcelona, 2014).

Sin embargo, se trata de un turista que se ha ido «seniorizando» con el paso del tiempo. Tal como puede apreciarse (Gráfico 3), en 1990 el turista-tipo lo conformaba una persona entre 35 y 44 años, grupo que asimismo conformaba casi la mitad del total de turistas. A su vez, los turistas mayores de 45 años tan solo representaban el 18\% del total. En 2013, estos ya representaban más del $45 \%$. El incremento ha sido especialmente notable en el segmento de más edad (de 55 o más años), que ha pasado de ser marginal a representar alrededor del 15\%. Por el contrario, el grupo de 25 a 34 años ha visto cómo su cuota se reducía a la mitad en este periodo, y pasaba del 29 al 15\%. En todo caso, parte de este aumento es atribuible a factores globales ligados al envejecimiento de la población, el aumento de la esperanza y calidad de vida, y la mejora económica de la población no activa. Además, la estancia media ha sido de 2,2 noches, lo que representa un 10\% más con respecto al 2009 (Ayuntamiento de Barcelona, 2014). 


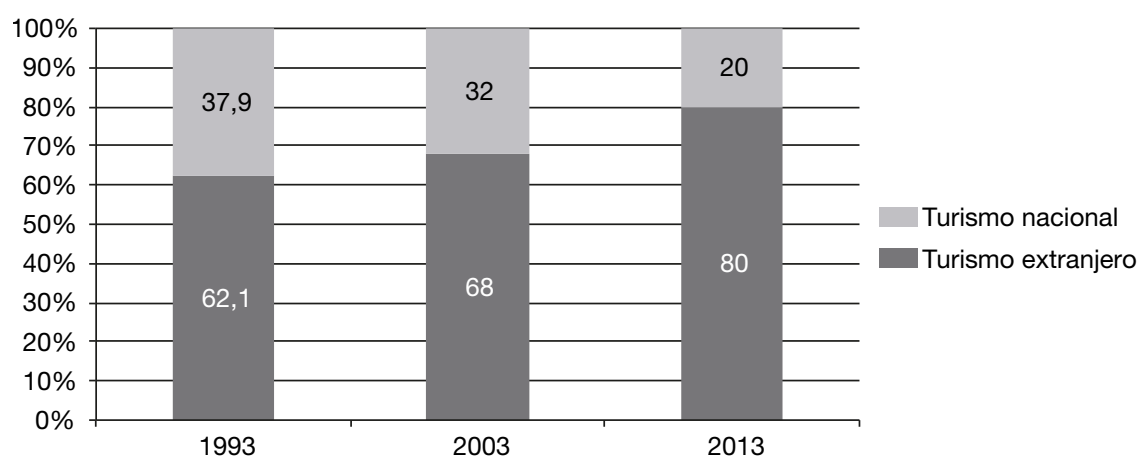

Gráfico 4. Procedencia de los turistas en Barcelona.

Fuente: elaboración propia a partir de datos de Turisme de Barcelona (2015a).

Otro cambio importante ocurrido en estos últimos años ha sido la continua pérdida de peso relativo del turismo nacional en detrimento del turismo extranjero. Si a principios de los años noventa el turismo nacional representaba alrededor de la tercera parte del total, actualmente esta cifra se ha reducido hasta la quinta parte. Esta caída ha sido especialmente intensa únicamente a partir de 2007, coincidiendo con el inicio de la crisis económica y la fuerte caída del consumo interno (Gráfico 4).

De hecho, el peso de los diferentes mercados internacionales ha ido modificándose a lo largo de estas últimas décadas. Si en la Barcelona inmediatamente postolímpica Francia e Italia eran los principales países emisores, por su dimensión, proximidad y economía, esta situación empezó a alterarse a finales de los noventa con la irrupción del turismo procedente del Reino Unido y la aparición de un incipiente turismo procedente de Norteamérica, mercados que ya han superado a Alemania (Tabla 5). Además, cabe destacar la creciente desconcentración del turismo, de modo que mientras los cuatro principales orígenes tendían a copar la mitad del mercado hasta 2007, esta cifra ha caído por debajo del $40 \%$ en los últimos años, elemento muy interesante en términos de diversificación del riesgo.

Tabla 5. Peso porcentual de los principales mercados internacionales en la ciudad de Barcelona

\begin{tabular}{|c|c|c|c|c|c|c|c|}
\hline \multicolumn{2}{|l|}{1993} & \multicolumn{2}{|l|}{2000} & \multicolumn{2}{|l|}{2007} & \multicolumn{2}{|l|}{2013} \\
\hline Francia & 14,5 & Norteamérica* & 21,1 & Reino Unido & 15,6 & Francia & 10,5 \\
\hline Italia & 13,8 & Gran Bretaña** & 16,9 & Italia & 12,4 & Estados Unidos & 10,4 \\
\hline Norteamérica* & 12,6 & Italia & 9,0 & Estados Unidos & 10,6 & Reino Unido & 10,4 \\
\hline Alemania & 11,3 & Alemania & 8,3 & Francia & 9,0 & Italia & 7,5 \\
\hline
\end{tabular}

* Incluye Estados Unidos y Canadá

** Incluye el Reino Unido e Irlanda

Fuente: elaboración propia a partir de datos de Turisme de Barcelona (2015a). 


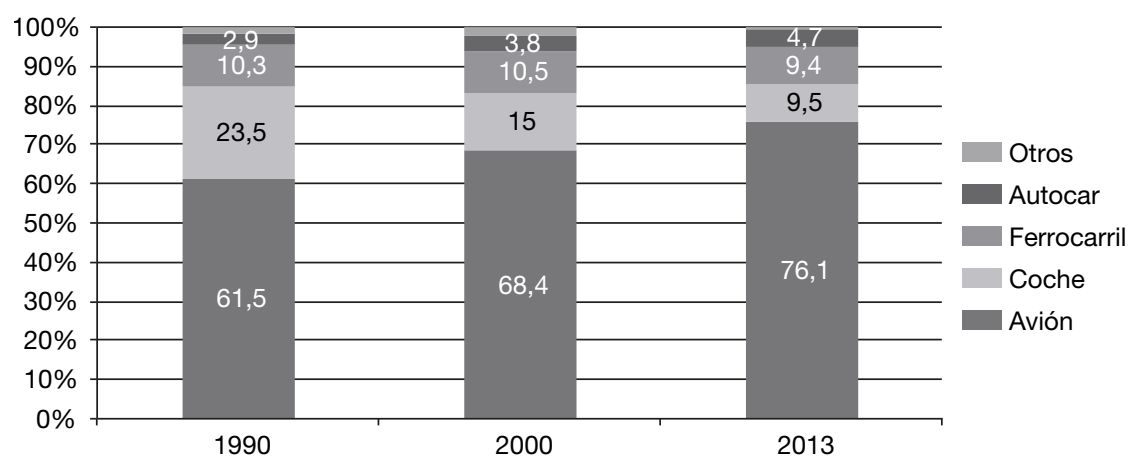

Gráfico 5. Turistas por transporte utilizado para llegar a Barcelona.

Fuente: elaboración propia a partir de datos de Turisme de Barcelona (2015a).

Esta estructura de mercados, con un fuerte peso del turismo internacional, contrasta con la de los ámbitos geográficos de referencia más cercanos. Así, de acuerdo con los datos de la Encuesta de Ocupación Hotelera del INE, el peso del turismo nacional era de tan solo el 20,1\% en Barcelona, frente al 36,7\% en el conjunto de Cataluña, o el 51\% en Madrid y el 50,8\% en el conjunto de España.

Otro factor diferencial reside en el peso de los mercados extranjeros. En efecto, el peso de los mercados comunitarios en el caso de Barcelona se sitúa en el 54,4\% del total de extranjeros, 12 puntos por encima de Madrid, pero 8 puntos inferior a la media catalana y 18 puntos inferior a la media nacional. Este diferencial de visitantes extranjeros con respecto a Madrid se explica en buena parte por el mayor peso relativo entre los extranjeros de los mercados franceses, alemanes y británicos en el caso de Barcelona. Por el contrario, el peso de los mercados estadounidense y japonés es, en términos relativos, ligeramente superior en Madrid.

Por otra parte, el avión ha ido ganando cuota de mercado como medio de locomoción principal para llegar a Barcelona, ya que se ha incrementado en 15 puntos desde 1990 (Gráfico 5), mientras que el automóvil ha perdido cuota de mercado (se ha reducido 14 puntos) y el acceso mediante ferrocarril se ha estabilizado alrededor del $10 \%$. Este auge del avión no es ajeno a la proliferación de vuelos de compañías de bajo coste (ELFAA, 2004; Hernández, 2008).

En cuanto a la estacionalidad de los turistas 5 (Gráficos 6 y 7), Barcelona presenta mínimos en el mes de enero (5,3\% del total de turistas de 2013$)$ y máximos en los meses de verano (10,1\% del total de turistas de 2013 en

5. La estacionalidad turística tiene importantes impactos negativos en los destinos (Cardona, 2014). Así, Hinch y Jackson (2000) creen que genera bajas rentabilidades. Asimismo provoca una contratación de personal muy discontinua (Koenig y Bischoff, 2005) y también en el suministro de servicios públicos (Murphy, 1985), ineficiencia de las instalaciones (Sutcliffe y Sinclair, 1980) y daños en los recursos naturales (Manning y Powers, 1984). El único elemento positivo es que la temporada baja permite descansar y reparar o mejorar las infraestructuras y el entorno (Andriotis, 2005; Vargas, Porras y Plaza, 2014). 

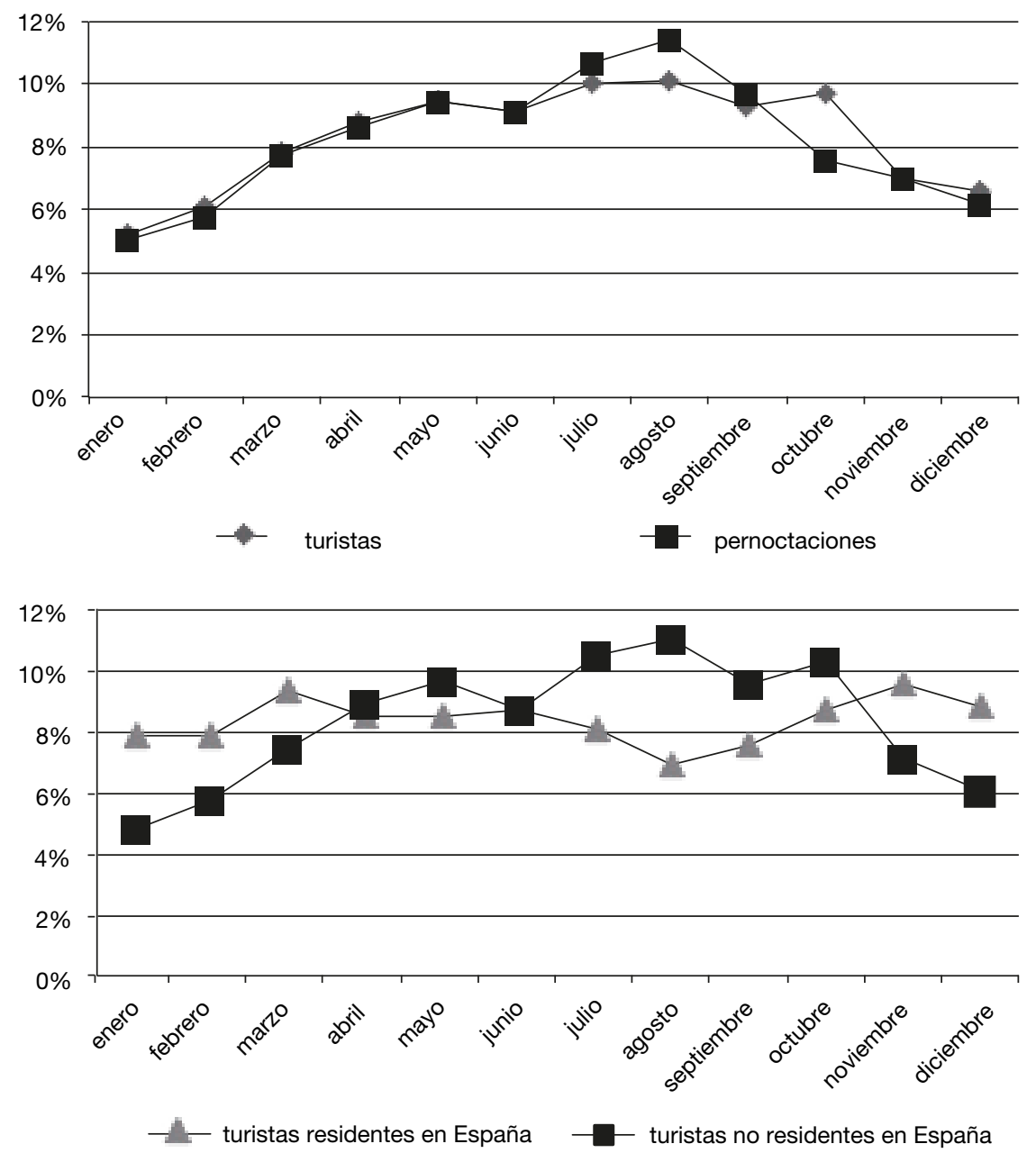

Gráfico 6 (a y b). Turistas y pernoctaciones (2013).

Fuente: elaboración propia a partir de datos de Turisme de Barcelona (2015a).

agosto). Esta situación la sitúa más cercana a la del conjunto de España que a la de Madrid, por ejemplo, en la que los meses de verano son de temporada baja. Esta estacionalidad es ligeramente más acusada por lo que respecta a pernoctaciones. Así, estas representaron el 11,4\% del total anual en agosto de 2013, mientras que las de enero del mismo año únicamente supusieron el 5\% del total (Gráficos 6a y 6b).

Analizando la estacionalidad por mercados emisores, hay una importante diferencia entre los residentes en España y los extranjeros. La demanda turís- 


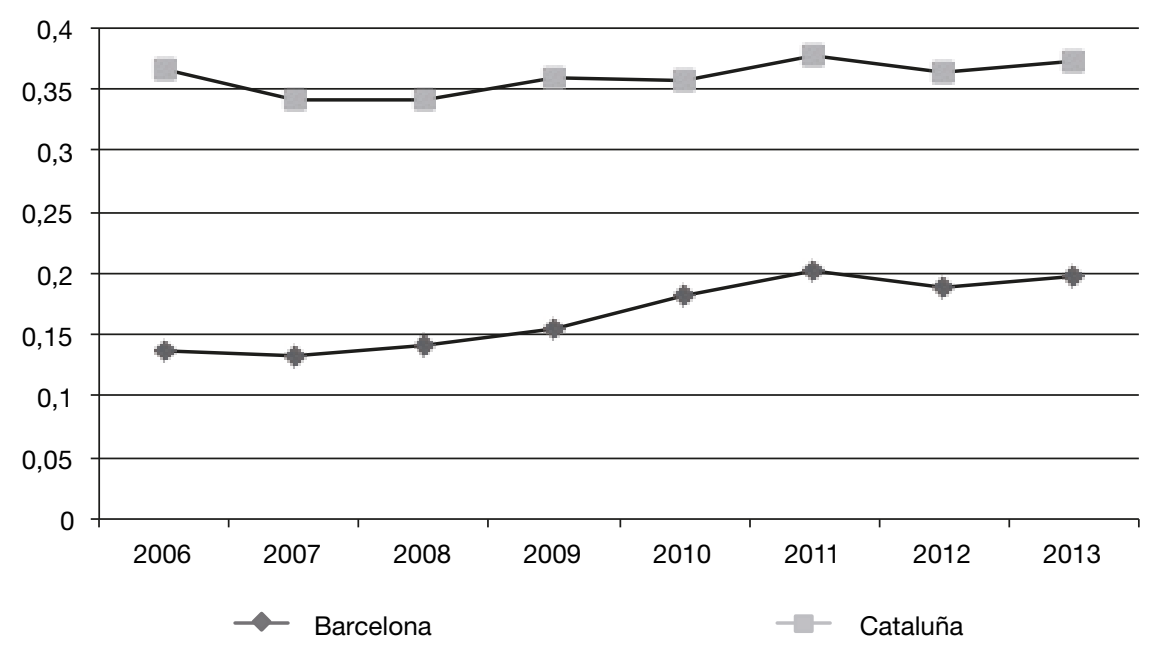

Gráfico 7. Evolución de la concentración mensual de viajeros hoteleros en Barcelona y Cataluña (2006-2013).

Nota: el coeficiente de variación es la desviación típica dividida por la media.

Fuente: elaboración propia a partir de datos de Encuesta de Ocupación Hotelera (INE).

tica en el caso de los nacionales es sensiblemente más estable. Asimismo, en el caso de los visitantes nacionales, los máximos anuales se ubican en periodos de entretiempo, mientras que en los extranjeros los máximos anuales se producen en verano. Esto es especialmente remarcable en el caso del mercado francés, que concentra en agosto el 15\% del total, pero también en mercados como el italiano o el británico. En el caso del mercado estadounidense, los máximos anuales se concentran en los meses de julio y junio, mientras que, en el caso del mercado alemán, los valores máximos se dan en los meses de octubre y mayo.

En todo caso, la estacionalidad de la demanda en Barcelona capital no es especialmente elevada si la evaluamos de manera sintética y comparativa, más allá de la observación mensual. Por ejemplo, si computamos el coeficiente de variación mensual como índice que aproxima el grado de concentración intermensual de los viajeros hoteleros, en el caso de la capital catalana este arrojaría en 2013 un valor de 0,198, cifra claramente menor, por ejemplo, que el valor arrojado para toda Cataluña $(0,374)^{6}$.

Sin embargo, se ha producido una evolución de este concepto, coincidiendo con la fase expansiva de la demanda. Entre 2006 y 2013, el coeficiente de variación ha ascendido desde 0,138 al anterior 0,198 , lo que representa un ascenso del 43\%. Aunque el indicador se estabiliza desde 2011 no deja de ser subrayable esta evolución en los últimos años (Gráfico 7).

6. Se puede interpretar también como que la desviación normal de un mes en Barcelona es de solo el 19,8\% con respecto a la media mensual. En Cataluña esta desviación sería del 37,4\%. 
Esta tendencia es similar a la de otros destinos urbanos (Cardona, 2014), por lo que las estrategias para reducir la estacionalidad en una gran ciudad como Barcelona exigen desarrollar nuevas actividades (eventos, festivales, congresos, etc.) que sirvan de reclamo turístico (Cuccia y Rizzo, 2011) o desviar a los turistas hacia las temporadas bajas mediante agresivas políticas de precios (Butler y Mao, 1997) o diseñando circuitos turísticos específicos para dichas fechas (Allcok, 1996; Capó, Riera y Rosselló, 2007).

En resumen, la demanda turística de Barcelona presenta un perfil de turista masculino, de mediana edad, extranjero comunitario (con una importante diversificación de mercados), que pernocta en la ciudad 2,2 noches, viene en avión y cuya visita no presenta una estacionalidad muy marcada, pero que está creciendo de manera significativa en estos últimos años.

\section{Oferta de alojamientos turísticos en Barcelona y su ubicación}

El creciente atractivo de la ciudad de Barcelona no puede entenderse sin el fuerte incremento de la oferta turística. Si en los años ochenta y noventa esta actuó como un importante freno al potencial turístico de Barcelona, esta situación empezó a revertir a partir de principios de la pasada década. Así, en 1990 la oferta hotelera de Barcelona se basaba en 118 establecimientos y 18.569 plazas hoteleras $^{7}$. El perfil de establecimiento tipo era el de un hotel de tres estrellas, situado en el distrito central de negocios (que correspondería básicamente al eje paseo de Gracia - tramo central de la avenida Diagonal) (Romero, 1990). Esta situación es radicalmente diferente en la actualidad (Tabla 6) y, por ejemplo, en 2013, las plazas hoteleras ofertadas se habían incrementado en un $241,7 \%$ con respecto a las de 1990. Este incremento se ha debido especialmente a la gran ampliación de la oferta de hoteles de cuatro estrellas, que, tras multiplicar por seis su capacidad, constituye actualmente cerca de la mitad de la oferta total. Por el contrario, la oferta hotelera de menor categoría ha crecido a un ritmo sustancialmente inferior.

Esta evolución de la oferta hotelera en su globalidad no parece haber afectado de manera negativa a las tasas de ocupación, que, según los datos de la Encuesta de Ocupación Hotelera del INE, han pasado del 63,6\% en 2006 al 63,8\% en 2013 (cuando las plazas habrían pasado en media anual de 48.200 a 70.432 según INE).

Otro cambio importante ha sido la localización de los establecimientos hoteleros, cuyo centro de gravedad se ha ido desplazando en estos últimos años en dirección al frente marítimo. Para analizar esta dinámica hay que circunscribirse al periodo 2004-2013, cuando están disponibles los datos desagregados por distritos ${ }^{8}$.

7. Los datos de 1990 no incluyen las pensiones, que en ese momento se consideraban un producto que no encajaba con la actividad turística. Se estima que en ese momento sumaban alrededor de 4.000 plazas en total. Ese mismo año, los hostales se equipararon a los hoteles y desaparecieron como categoría independiente.

8. Barcelona está dividida en 10 distritos desde 1983 (Ciutat Vella, Eixample, Gràcia, Horta-Guinardó, Sant Andreu, Sant Martí, Sants-Montjüich, Les Corts, Sarrià-Sant Gervasi, y Nou Barris). Los distritos de Eixample y Ciutat Vella corresponden al centro de la ciudad, y en ellos se ubican la gran mayoría de las atracciones turísticas, así como una parte importante de la oferta comercial. 
Tabla 6. Evolución de la oferta de plazas hoteleras en Barcelona por categoría

\begin{tabular}{lrrc}
\hline \multicolumn{1}{c}{ Categoría } & $\mathbf{1 9 9 0}$ & $\mathbf{2 0 1 3}$ & Crecimiento (\%) \\
\hline 5 estrellas & 3.979 & 9.097 & 128,6 \\
4 estrellas & 5.302 & 33.695 & 535,5 \\
3 estrellas & 6.375 & 14.967 & 134,8 \\
2 estrellas & 1.466 & 3.408 & 132,5 \\
1 estrella & 1.447 & 2.278 & 57,4 \\
Total & 18.569 & 63.445 & 241,7 \\
\hline
\end{tabular}

Nota: Los datos de 2013 incluyen de manera separada los hoteles de 5 estrellas Gran Lujo y 4 estrellas superior, que en este trabajo se han asimilado a 5 y 4 estrellas, respectivamente.

Fuente: elaboración propia a partir de López Palomeque (1995) y Ayuntamiento de Barcelona.

Si se analiza la distribución territorial en la capital catalana, en el año 2013, del número absoluto de alojamientos turísticos y de plazas de este tipo, según datos del Ayuntamiento de Barcelona (2014) se obtienen los dos gráficos siguientes (Gráfico 8a y Gráfico 8b, respectivamente).

En ellos se puede apreciar una concentración espacial de alojamientos en los distritos de Ciutat Vella (con 213) y del Eixample (con 212), seguidos por los restantes distritos limítrofes con la costa (Sant Martí y Sants-Montjuïc) y Sarrià-Sant Gervasi. Por el contrario, los distritos con menos alojamientos de este tipo son Nou Barris y Sant Adrià, donde solamente hay dos en cada uno de ellos. En cuanto al número de plazas disponibles, también destacan los distritos de Ciutat Vella (con 20.114) y del Eixample (con 17.982). En relación con la capacidad media de estos alojamientos, calculando las plazas por alojamiento, el distrito donde esta densidad de plazas es mayor es el de Sant Martí (con 317,9 plazas/aloj.), seguido por Sarrià-Sant-Gervasi (con 235,5), Sants-Montjuïc (con 170,5) y Nou Barris (con 158), mientras que el que tiene una menor densidad es Gràcia (con 51,9).

En todo caso, se observa que en 2013 el 35\% de los establecimientos se localizaban en Ciutat Vella y otro tanto en el Eixample (por tanto, el 70\% del total se encontraban en solo estos dos distritos). Sin embargo, las dinámicas diferenciales han provocado desde 2004 una reducción del peso de Ciutat Vella (que aportaba inicialmente el $44 \%$ ) y un aumento de la zona del Eixample (que ha pasado del $27 \%$ al $35 \%$ ). En términos de plazas se produce el mismo fenómeno, ya que Ciutat Vella sigue aportando la parte más importante en 2013, con el 29\% (32\% en 2004), seguida por el Eixample, con el $26 \%$ (24\% en 2004).

Otro dato de interés consiste en analizar la distribución de la oferta por categorías y distritos en los años 2004 y 2013 (Tablas 7 y 8 y Gráficos 9a y 9b). Desgraciadamente esta información solo está disponible para los últimos años, con lo que se pierde la oportunidad de analizar la dinámica y observar si se han producido cambios de especialización.

A su vez, los gráficos 10a y $10 \mathrm{~b}$ presentan la distribución porcentual espacial de las plazas hoteleras en estos dos años, mientras que los gráficos 11a, 11b 

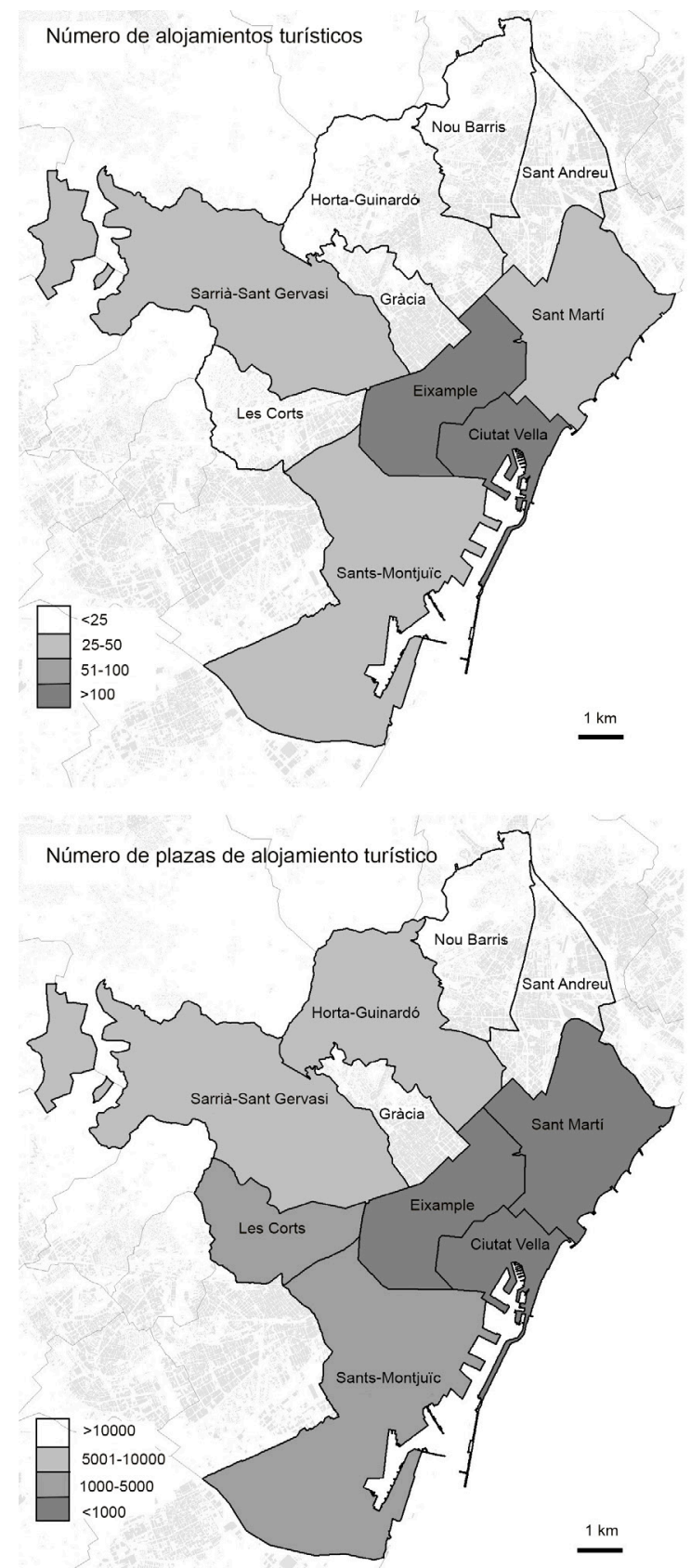

Gráfico 8 (a y b). Distribución de los alojamientos turísticos (año 2013).

Fuente: elaboración propia a partir de datos del Anuario Estadístico Municipal 2014, Ayuntamiento de Barcelona. Aplicación cartográfica: MiraMon. 
Tabla 7. Distribución porcentual de establecimientos hoteleros por categoría por distrito (2013)

\begin{tabular}{|c|c|c|c|c|c|c|c|c|c|c|}
\hline & $\begin{array}{l}\text { Ciutat } \\
\text { Vella }\end{array}$ & Eixample & Sants & Les Corts & $\begin{array}{c}\text { Sarrià- } \\
\text { Sant } \\
\text { Gervasi }\end{array}$ & Gràcia & $\begin{array}{l}\text { Horta- } \\
\text { Guinardó }\end{array}$ & $\begin{array}{l}\text { Nou } \\
\text { Barris }\end{array}$ & $\begin{array}{c}\text { Sant } \\
\text { Andreu }\end{array}$ & $\begin{array}{l}\text { Sant } \\
\text { Martí }\end{array}$ \\
\hline Hoteles & 82,9 & 90,8 & 88,1 & 93,7 & 78,2 & 68,6 & 87,8 & 84,6 & 100,0 & 97,2 \\
\hline Gran lujo & 13,6 & 7,4 & 2,0 & 13,0 & 4,2 & 19,9 & 0,0 & 0,0 & 0,0 & 0,0 \\
\hline 5 estrellas & 4,4 & 3,7 & 0,0 & 25,3 & 0,0 & 0,0 & 0,0 & 0,0 & 0,0 & 0,7 \\
\hline 4 estrellas superior & 4,3 & 4,3 & 14,8 & 18,5 & 0,0 & 0,0 & 0,0 & 0,0 & 0,0 & 8,2 \\
\hline 4 estrellas & 20,7 & 44,3 & 61,9 & 23,9 & 29,3 & 0,0 & 45,7 & 0,0 & 0,0 & 68,2 \\
\hline 3 estrellas & 27,7 & 24,4 & 4,1 & 10,5 & 37,7 & 38,1 & 4,0 & 0,0 & 100,0 & 13,4 \\
\hline 2 estrellas & 6,6 & 4,7 & 2,9 & 2,5 & 6,9 & 3,0 & 22,3 & 84,6 & 0,0 & 2,5 \\
\hline 1 estrellas & 5,5 & 1,9 & 2,5 & 0,0 & 0,0 & 7,6 & 15,7 & 0,0 & 0,0 & 4,3 \\
\hline Hoteles-apartamento & 0,6 & 0,9 & 0,5 & 5,4 & 14,9 & 0,0 & 9,0 & 0,0 & 0,0 & 2,4 \\
\hline 4 estrellas & 0,0 & 0,3 & 0,0 & 5,4 & 10,3 & 0,0 & 0,0 & 0,0 & 0,0 & 2,4 \\
\hline 3 estrellas & 0,6 & 0,0 & 0,5 & 0,0 & 4,0 & 0,0 & 0,0 & 0,0 & 0,0 & 0,4 \\
\hline 2 estrellas & 0,0 & 0,6 & 0,0 & 0,0 & 0,6 & 0,0 & 0,0 & 0,0 & 0,0 & 0,2 \\
\hline 1 estrellas & 0,0 & 0,0 & 0,0 & 0,0 & 0,0 & 0,0 & 9,0 & 0,0 & 0,0 & 0,1 \\
\hline Pensiones & 16,5 & 8,4 & 11,4 & 0,8 & 6,9 & 31,4 & 3,3 & 15,4 & 0,0 & 9,3 \\
\hline
\end{tabular}

Fuente: elaboración propia a partir de datos del Anuario Estadístico Municipal 2014, Ayuntamiento de Barcelona.

Tabla 8. Distribución porcentual de plazas hoteleras por distrito según categoría (2013)

\begin{tabular}{|c|c|c|c|c|c|c|c|c|c|c|}
\hline & $\begin{array}{l}\text { Ciutat } \\
\text { Vella }\end{array}$ & Eixample & Sants & Les Corts & $\begin{array}{c}\text { Sarrià- } \\
\text { Sant } \\
\text { Gervasi }\end{array}$ & Gràcia & $\begin{array}{l}\text { Horta- } \\
\text { Guinardó }\end{array}$ & $\begin{array}{c}\text { Nou } \\
\text { Barris }\end{array}$ & $\begin{array}{c}\text { Sant } \\
\text { Andreu }\end{array}$ & $\begin{array}{l}\text { Sant } \\
\text { Martí }\end{array}$ \\
\hline Total & 29,5 & 26,7 & 10,1 & 8,7 & 5,5 & 1,4 & 1,5 & 0,5 & 0,3 & 15,9 \\
\hline Hoteles & 27,6 & 27,4 & 10,0 & 9,3 & 4,8 & 1,1 & 1,5 & 0,4 & 0,4 & 17,4 \\
\hline Gran lujo & 51,2 & 25,1 & 2,6 & 14,5 & 2,9 & 3,6 & 0,0 & 0,0 & 0,0 & 0,0 \\
\hline 5 estrellas & 28,3 & 21,5 & 0,0 & 47,7 & 0,0 & 0,0 & 0,0 & 0,0 & 0,0 & 2,5 \\
\hline 4 estrellas superior & 18,5 & 16,8 & 21,9 & 23,8 & 0,0 & 0,0 & 0,0 & 0,0 & 0,0 & 19,0 \\
\hline 4 estrellas & 15,5 & 30,1 & 15,9 & 5,3 & 4,1 & 0,0 & 1,7 & 0,0 & 0,0 & 27,5 \\
\hline 3 estrellas & 38,7 & 30,8 & 2,0 & 4,3 & 9,8 & 2,6 & 0,3 & 0,0 & 1,5 & 10,0 \\
\hline 2 estrellas & 37,2 & 23,9 & 5,5 & 4,2 & 7,2 & 0,8 & 6,3 & 7,4 & 0,0 & 7,6 \\
\hline 1 estrellas & 47,8 & 14,9 & 7,3 & 0,0 & 0,0 & 3,2 & 6,9 & 0,0 & 0,0 & 19,9 \\
\hline Hoteles-apartamento & 7,4 & 10,4 & 2,3 & 21,0 & 36,1 & 0,0 & 5,9 & 0,0 & 0,0 & 16,9 \\
\hline 4 estrellas & 0,0 & 4,7 & 0,0 & 31,8 & 37,8 & 0,0 & 0,0 & 0,0 & 0,0 & 25,6 \\
\hline 3 estrellas & 38,3 & 0,0 & 11,7 & 0,0 & 50,0 & 0,0 & 0,0 & 0,0 & 0,0 & 0,0 \\
\hline 2 estrellas & 0,0 & 83,6 & 0,0 & 0,0 & 16,4 & 0,0 & 0,0 & 0,0 & 0,0 & 0,0 \\
\hline 1 estrellas & 0,0 & 0,0 & 0,0 & 0,0 & 0,0 & 0,0 & 100,0 & 0,0 & 0,0 & 0,0 \\
\hline Pensiones & 52,2 & 23,9 & 12,3 & 0,8 & 4,1 & 4,8 & 0,5 & 0,8 & 0,0 & 0,6 \\
\hline
\end{tabular}

Fuente: elaboración propia a partir de datos del Anuario Estadístico Municipal 2014, Ayuntamiento de Barcelona. 

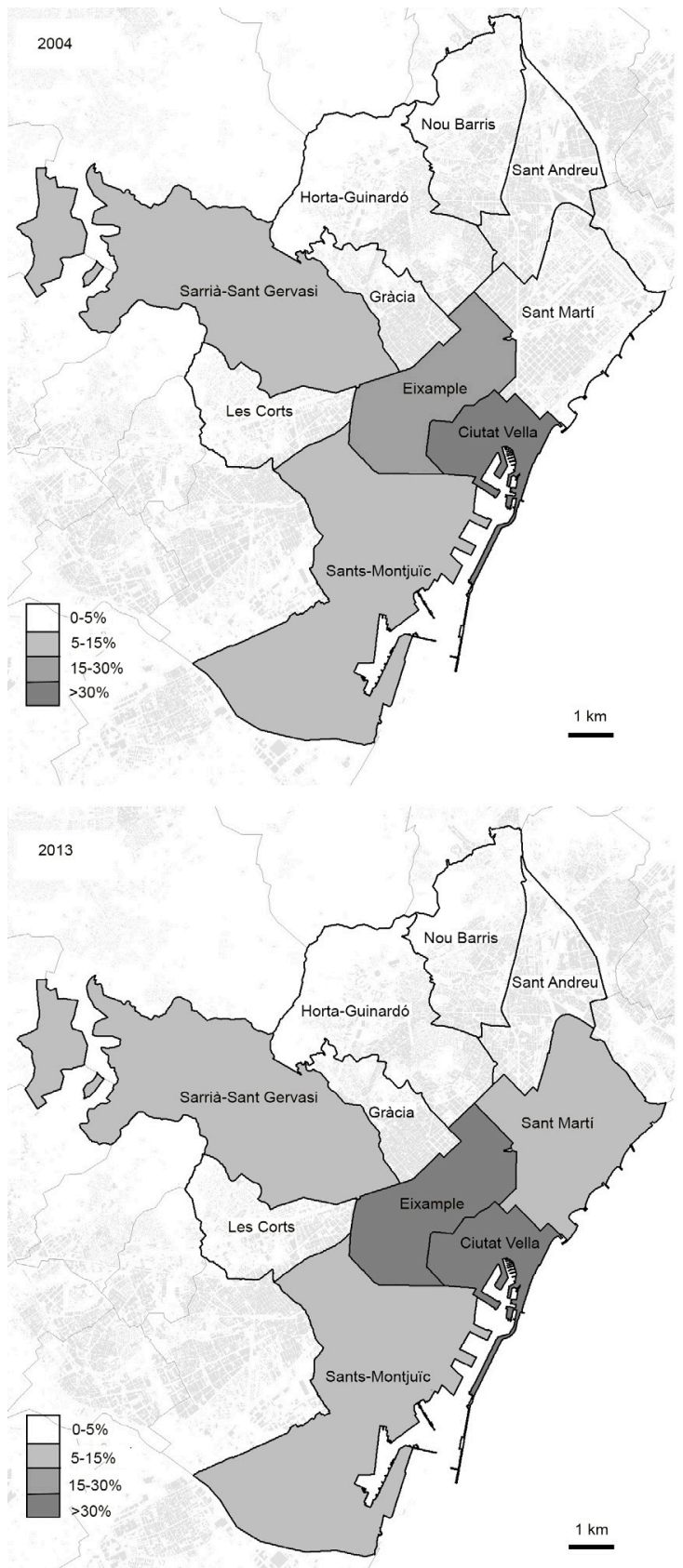

Gráfico 9 (a y b). Distribución porcentual de establecimientos hoteleros por distritos.

Fuente: elaboración propia, a partir de datos del Anuario Estadístico Municipal 2014, Ayuntamiento de Barcelona. Aplicación cartográfica: MiraMon. 

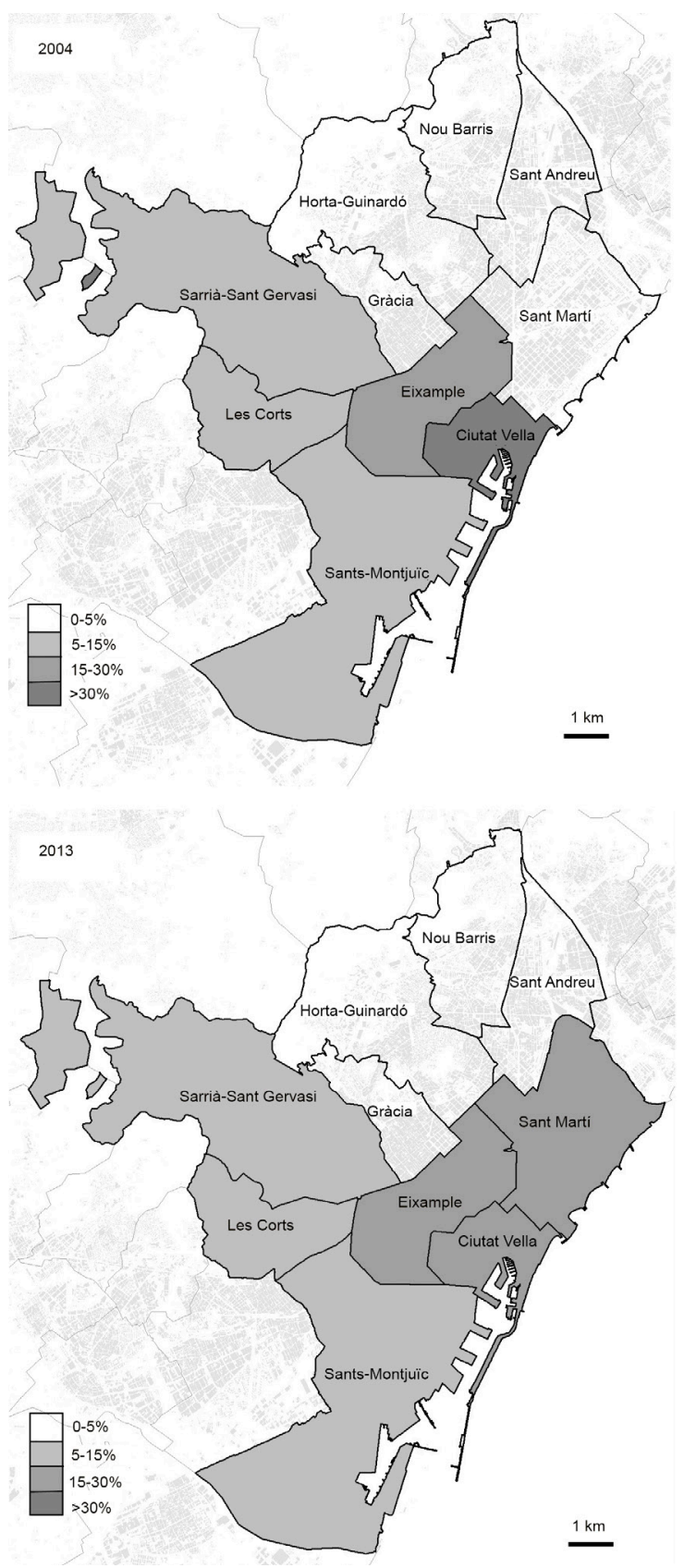

Gráfico 10 (a y b). Distribución porcentual de plazas hoteleras por distritos.

Fuente: elaboración propia a partir de datos del Anuario Estadístico Municipal 2014, Ayuntamiento de Barcelona. Aplicación cartográfica MiraMon. 

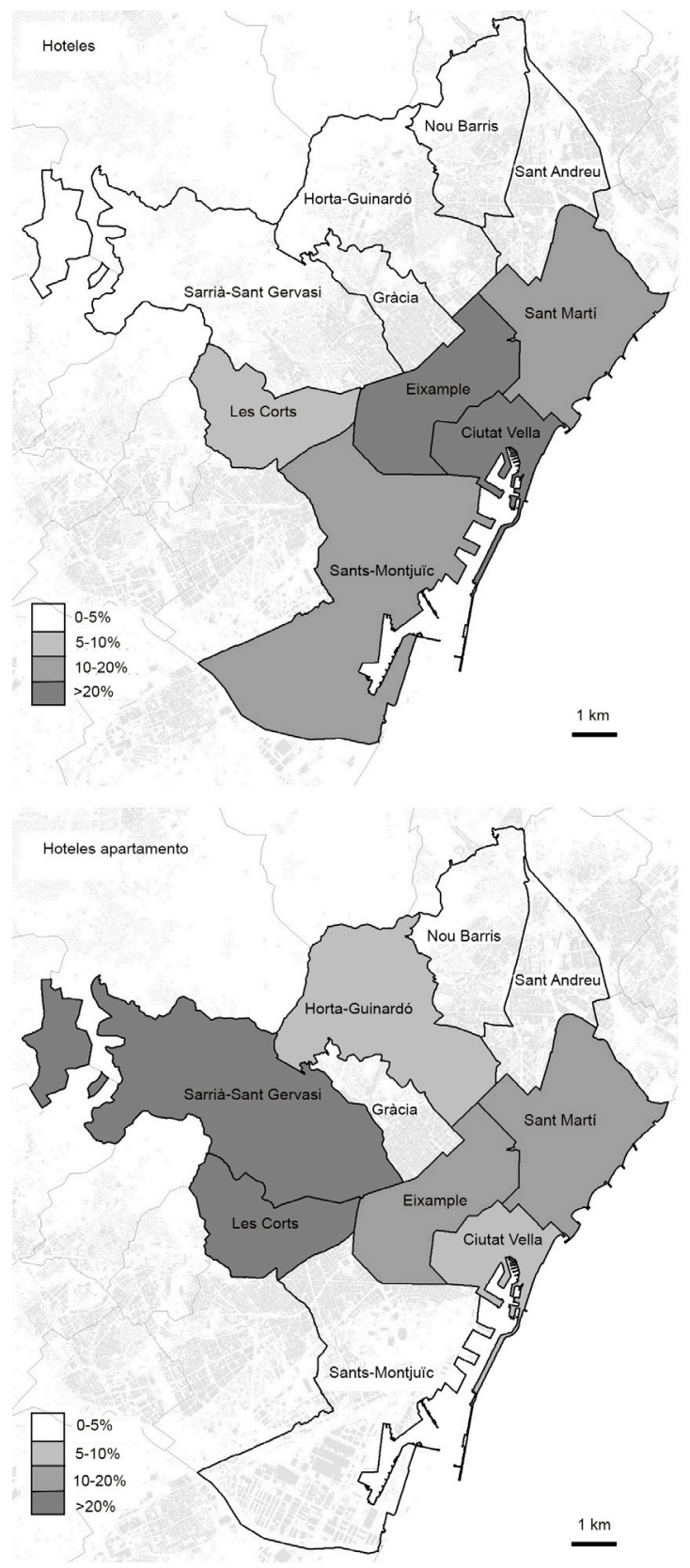

Gráfico 11 (a y b). Distribución de las plazas de hoteles y hoteles-apartamentos por distrito (año 2013).

Fuente: elaboración propia a partir de datos del Anuario Estadístico Municipal 2014, Ayuntamiento de Barcelona. Aplicación cartográfica MiraMon. 


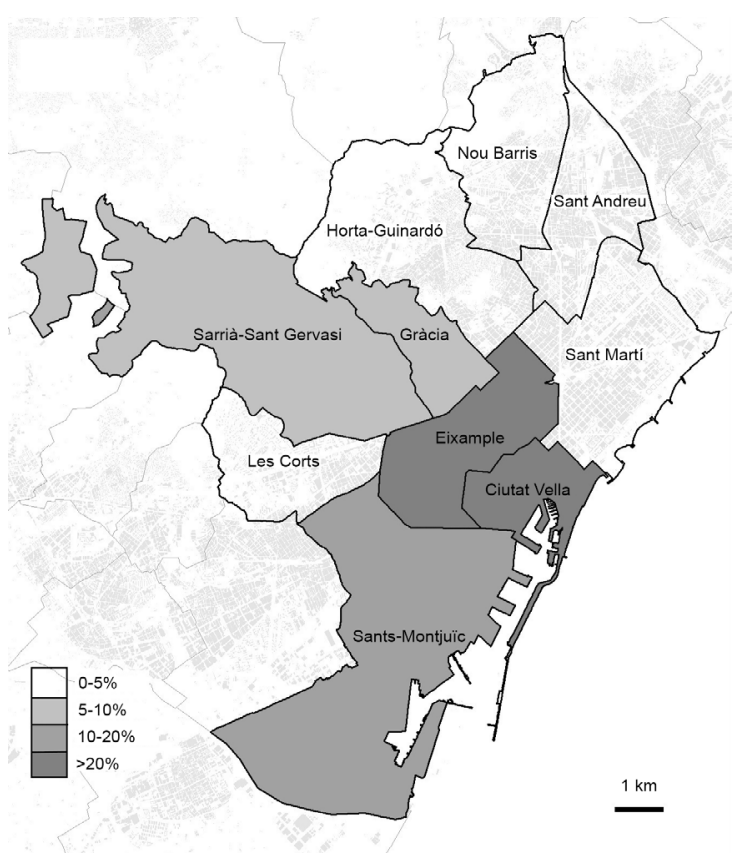

Gráfico 12. Distribución de las plazas de pensiones por distrito (2013).

Fuente: elaboración propia con MiraMon a partir de datos del Anuario Estadístico Municipal, Ayuntamiento de Barcelona.

y 12 hacen lo mismo solamente para el año 2013 pero por categoría de producto. Un análisis inicial nos indicaría que Ciutat Vella es un distrito fuertemente polarizado, ya que una séptima parte de sus plazas hoteleras son de gran lujo, pero al mismo tiempo una sexta parte de su oferta es de pensiones. En cambio, el Eixample, Sant Martí y Sants-Montjuïc presentan una estructura basada en hoteles de cuatro estrellas, mientras que Les Corts se especializa en una oferta de turismo superior, basada en establecimientos de lujo.

El distrito de Ciutat Vella concentra el 52\% de plazas en pensiones del conjunto de la ciudad (Tabla 8). Por otro lado, es también donde hay un mayor porcentaje de plazas hoteleras de la ciudad (27,6\%), seguido a muy corta distancia del Eixample (27,4\%). Por categorías, Ciutat Vella acapara la oferta de plazas de Gran Lujo (51,2\%), pero también de las categorías inferiores a cuatro estrellas. Les Corts concentra cerca de la mitad de la oferta de cinco estrellas. Los hoteles de cuatro estrellas y cuatro estrellas superior son los que más repartidos están por la ciudad, y Les Corts es el distrito con mayor número de plazas en la primera categoría (23,8\% del total), mientras que en el segundo caso, el Eixample y Sant Martí copan más de la mitad de plazas de la categoría (30,15 y 27,5\%, respectivamente). Sarrià-Sant Gervasi, por su parte, concentra algo más de la tercera parte de la capacidad total de hoteles-apartamento. 
En su conjunto, el número de establecimientos hoteleros ha crecido un $44,6 \%$ en dicho periodo, mientras que el crecimiento del número de plazas ha sido del 79,2\% (Ayuntamiento de Barcelona, 2014). Este incremento, sin embargo, no ha sido uniforme entre distritos. Si bien casi todos ellos han ganado capacidad, tanto en número de establecimientos como en plazas hoteleras, este crecimiento ha sido especialmente importante en distritos como Sant Martí, donde la tasa acumulada de crecimiento de establecimientos y habitaciones ha sido del $227,3 \%$ y $660,4 \%$, respectivamente. Otro distrito que ha experimentado un fuerte crecimiento ha sido el Eixample, con un crecimiento acumulado del $89,3 \%$ por lo que respecta a establecimientos y del $96,9 \%$ en cuanto a habitaciones. Finalmente, cabe destacar también el caso de Ciutat Vella, donde la oferta de hoteles ha crecido un $62 \%$, y ello pese a tratarse de una zona donde entre 2009 y 2013 hubo una moratoria en la construcción de nuevas instalaciones.

Si se quiere relativizar las tasas de crecimiento de la oferta con el peso en cada distrito del número de establecimientos y plazas hoteleras, es útil computar las aportaciones de cada distrito al crecimiento municipal de los indicadores de oferta (Gráfico 13). Puede verse que una parte muy importante del crecimiento global de establecimientos hoteleros de esta década la ha aportado el distrito del Eixample, seguido a gran distancia por los distritos de Ciutat Vella y Sant Martí.

En el gráfico anterior también puede apreciarse que esta tendencia cambia si la unidad de medida son las plazas hoteleras. En este caso, es Sant Martí el distrito que ha aportado más al crecimiento de las plazas hoteleras en la ciudad

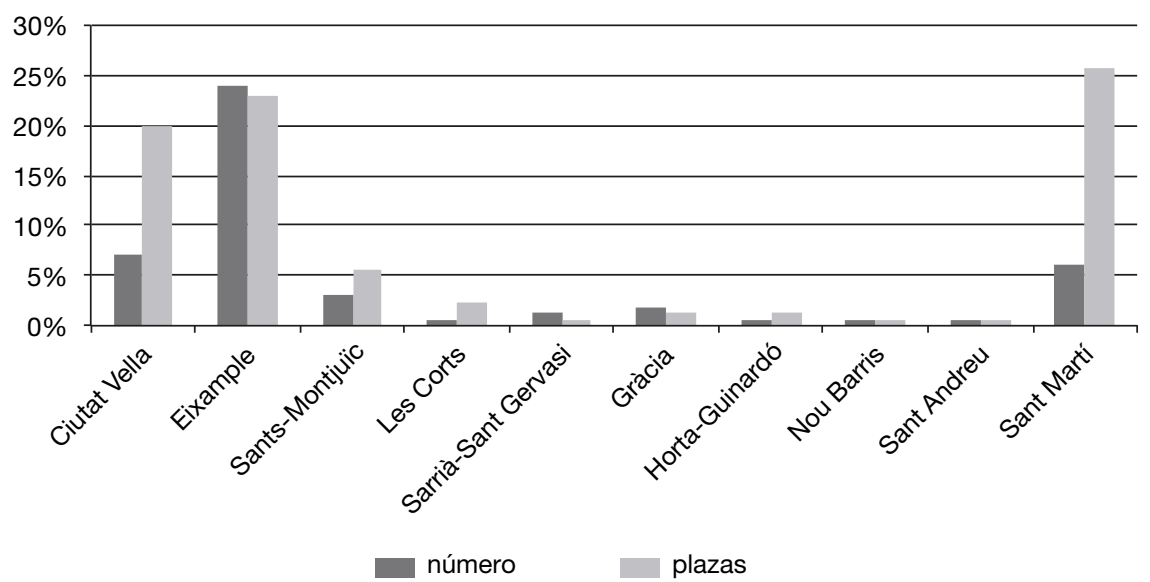

Gráfico 13. Contribuciones relativas al crecimiento porcentual de la oferta hotelera por distritos (2004-2013).

Fuente: elaboración propia a partir de datos del Anuario Estadístico Municipal 2014, Ayuntamiento de Barcelona. 
en este período, con una cuarta parte del incremento global. El Eixample y Ciutat Vella explican entre ambas la mayor parte del resto. El crecimiento en otras zonas es anecdótico salvo en el distrito de Sants-Montjuïc, una zona con importantes infraestructuras relacionadas con el turismo. Todos estos cambios han conllevado una situación curiosa: la concentración de la oferta de alojamientos turísticos oficiales se redujo levemente en el periodo 2004-2013. Concretamente, el índice de Herfindahl (cuya expresión responde al sumatorio de los pesos relativos al cuadrado) pasó de 0,28 a 0,26 por lo que respecta a establecimientos, y de 0,21 a 0,20 en cuanto a plazas ofertadas.

En conclusión, pese a que los datos muestran una cierta tendencia a la desconcentración en la última década, no es menos cierto que la oferta de alojamientos turísticos sigue altamente concentrada en los distritos «tradicionales» de Ciutat Vella y del Eixample, y de manera especial la de aquellos establecimientos de menor categoría, en el primer caso. Esta tendencia es similar a la de otras grandes ciudades, ya que la localización urbana de los hoteles depende de una serie de factores, diferentes según la categoría del establecimiento, antigüedad, accesibilidad, infraestructuras públicas y el efecto de aglomeración (Shoval, N., Mc Kercher, B. Erica, N. G. y Amit, B., 2011; Yang, Wong y Yang, 2012).

Quizá sea esta la razón, conjuntamente con la eclosión de una oferta de alojamiento turístico alternativa a los hoteles, que explique un cierto desencanto, cuando no hostilidad, de una parte de los vecinos de algún distrito, como Ciutat Vella, a la implantación de nuevos proyectos hoteleros?.

\section{Elementos de futuro}

Barcelona ha pasado de ser una ciudad industrial y de servicios, asociada a la capitalidad regional, a especializarse en servicios con alto valor añadido y turístico. Barcelona ha apostado por el desarrollo del turismo urbano y en la actualidad ya es una capital turística de primer nivel, siguiendo la máxima de la teoría clásica del comercio internacional, que dice que los países (o los territorios) deben especializarse en aquellos bienes que utilizan de manera intensa los factores para los cuales poseen ventaja comparativa (Mercado, 2000).

El aumento de la demanda turística en la ciudad, como ha quedado patente en las secciones anteriores, ha sido un gran éxito atribuible tanto a la política pública propia como a factores externos que lo han propiciado. Barcelona posee una buena composición de mercados, cada vez más diversificada y con un importante peso del mercado extranjero. Ha creado una "marca» internacional, asociada al cosmopolitismo, la creatividad y el nivel de vida. Tiene una oferta de alojamientos turísticos de primer nivel, de calidad y bien asentada, con continuos proyectos de renovación y de crecimiento.

9. Algunos movimientos vecinales se oponen a la construcción de nuevos hoteles en este barrio y sus reclamaciones aparecen en la prensa, como es el caso de La Vanguardia (11 de mayo de 2015), debido al impacto paisajístico, ambiental, de usos del barrio, patrimonial y de tranquilidad vecinal (<http://www.lavanguardia.com/vida/20150401/54429374900/ vecinos-de-ciutat-vella-se-oponen-a-nuevo-hotel-que-construye-nunez-y-navarro.html>). 
Sin embargo, esta evolución arroja algunas sombras que pueden obstaculizar su crecimiento futuro. Barcelona es una recién llegada a esta liga mundial de las grandes capitales turísticas mundiales y, como tal, es frágil. A nuestro entender, los principales problemas que implican estrategias de corrección, y que son claras amenazas futuras, serían los relacionados a continuación.

En primer lugar, la estacionalidad, que no siendo todavía excesivamente alta, ha aumentado en los últimos años, coincidiendo con una fase de crecimiento de la demanda y de la oferta. Los elevados flujos que recibe Barcelona deben distribuirse de manera adecuada a lo largo del año para no acercarse a límites que puedan disparar las externalidades negativas asociadas al crecimiento turístico (ruido, inseguridad, aparcamiento y tráfico, medioambiente y, en definitiva, resentimiento de la marca).

En segundo lugar, el gran incremento en los flujos se produce en un espacio muy concreto de la ciudad, en el que se concentran los principales recursos turísticos y equipamientos de alojamiento. Barcelona tiene un centro turístico pequeño en comparación con el resto de capitales turísticas. Esta situación dispara las externalidades negativas del crecimiento turístico y constituye una amenaza muy grave de cara al futuro. Por tanto, y previendo que los crecimientos continuarán siendo positivos en el futuro, es necesario diseñar e implementar estrategias de desconcentración territorial en la capital catalana. Una de ellas consistiría en favorecer la desconcentración en otros distritos de la ciudad, a partir de políticas de producto y promoción y de localización de oferta de alojamiento. En todo caso, estas estrategias pueden tener un impacto limitado. En este sentido, creemos que incluso pueden ser más útiles las políticas de desconcentración hacia otros destinos catalanes, más o menos lejanos. Esto es, Barcelona capital puede ser la más interesada en que se relocalicen flujos hacia las otras capitales catalanas de provincia (Gerona, Tarragona, Lérida), por la propia sostenibilidad de su crecimiento. Relocalización que habría de ir más allá de las excursiones de un día e incluir pernoctaciones. Además, la progresiva implantación de estos productos territoriales integrados coadyuvaría a enriquecer la propia experiencia turística de los visitantes, aumentar su fidelización y atraer nueva demanda. Por lo tanto, por la propia sostenibilidad de Barcelona, los turistas deberían cada vez más comprar la marca "Cataluña», y Barcelona debería actuar primordialmente como factor de atracción.

En tercer lugar, el desarrollo casi exponencial de la actividad turística genera problemas inmediatos y naturales ligados al crecimiento. Uno de los más negativos, si no el que más, es la emergencia de episodios de "conflictividad" entre residentes y turistas ${ }^{10}$. En este sentido, debido a la presión que ejerce la actividad en un espacio geográfico de la ciudad muy reducido, la Administra-

10. En el verano de 2014 los vecinos del barrio de la Barceloneta se quejaron de los problemas ocasionados por los turistas que pernoctaban en pisos turísticos, muchos de ellos ilegales, por lo que realizaron algunas movilizaciones de protesta, tal como reflejó el diario $E l$ Mundo el 21 de agosto (<http://www.elmundo.es/cataluna/2014/08/21/53f5b39322601d ae478b4577.html>). 
ción debería implementar medidas continuas de compatibilización del turismo urbano con la actividad y el nivel de vida de los residentes. En este sentido habría que tener en cuenta que: a) la ciudad debe velar por que se respeten las normas de convivencia en los espacios colectivos y la legalidad en lo que respecta a las actividades económicas; $b$ ) la ciudad debe utilizar parte de la recaudación que obtiene vía tasa turística para mejorar el nivel de vida de los residentes en las áreas de mayor concentración de la actividad; y c) la Administración debe realizar una gestión social continuada de la convivencia entre turismo y residentes, con esquemas continuados de participación social en las decisiones.

Y, finalmente, Barcelona ha de gestionar continuamente su «marca» en los mercados internacionales. Es difícil y laborioso ganarse un espacio en este sentido, pero es muy rápido perderlo. En este sentido, las estrategias de marketing y de redes sociales aparecen como claves en este proceso, así como contar en su diseño con la participación de todos los agentes de la ciudad.

\section{Conclusiones y consideraciones finales}

En este trabajo se ha revisado la posición y evolución de Barcelona como destino turístico en estas últimas décadas a partir de una pluralidad de indicadores cuantitativos disponibles. Seguidamente presentamos una síntesis de los principales resultados obtenidos.

En primer lugar, Barcelona ha crecido turísticamente en estas últimas décadas de forma muy significativa, lo que le ha permitido obtener una posición privilegiada a escala internacional. Es ya la sexta ciudad turística europea y la primera española por nivel de visitantes extranjeros, la tercera según gasto y la cuarta del mundo en cuanto a cruceristas. Este crecimiento turístico urbano está acorde con la evolución seguida al respecto por muchas de las otras grandes ciudades europeas, lo que confirma las pautas señaladas por la red European Cities Marketing (2014), entidad dedicada a mejorar la competitividad de las ciudades europeas, en su informe anual, y tal como ya apuntaron Wahab y Pigram en 1997.

En segundo lugar, el crecimiento de las entradas turísticas a la ciudad de Barcelona no se inició hasta principios de los noventa, con la celebración de los Juegos Olímpicos, y se ha incrementado significativamente en los últimos años, tanto en el número de turistas recibidos como en el de pernoctaciones, de manera que desde 2009 el aumento de las pernoctaciones hoteleras ha sido del $31 \%$, y el de la estancia media del $23 \%$ desde 2008 . Este patrón es particular de Barcelona y muy positivo porque frecuentemente los progresos de los flujos de turistas coinciden con reducciones en las estancias medias, que parcialmente los anulan. Para conseguirlo ha sido muy importante la colaboración entre las entidades públicas y privadas, tanto en la promoción de la ciudad como en la puesta a punto de sus infraestructuras, servicios y reurbanización urbana. Ello está en consonancia con lo indicado al respecto por autores como Benach y Tello (2004), Garay y Cànoves (2009) y Borja (2010). 
En tercer lugar, se están produciendo cambios en el comportamiento de la demanda. El turista que visita Barcelona se ha ido envejeciendo, con un aumento en el peso del colectivo mayor de 45 años (ya representa casi la mitad del total). Se ha ido internacionalizando (con una pérdida de peso del componente nacional, que ya se aproxima al $20 \%$ del total) y diversificando en cuanto a la estructura de los mercados de origen con la irrupción, por ejemplo, del turismo estadounidense, que ya representa el 10\% de turismo internacional, casi al mismo nivel que el británico. Todo ello sigue las pautas recomendadas por el Plan Estratégico de Turismo de la Ciudad de Barcelona (Ayuntamiento de Barcelona, 2009), realizado por el consorcio Turisme de Barcelona (2015b) con el objetivo de reforzar el atractivo turístico de esta ciudad y mantenerla internacionalmente en posiciones preferenciales. Sin embargo, la estacionalidad, sin ser especialmente grave, ha escalado en los últimos años con claridad. Este ascenso, unido al gran volumen de flujos que se recibe, constituye una amenaza para la sostenibilidad de la actividad.

En cuarto lugar, este crecimiento turístico ha venido acompañado por un ostensible aumento de la oferta hotelera, con un incremento del $242 \%$ desde 1990. Este fenómeno se explica fundamentalmente por la mayor oferta de hoteles de cuatro estrellas, que ahora representan cerca de la mitad del total. Este mayor sesgo de la oferta hacia la mayor calidad coincide con un movimiento del centro de gravedad espacial de la oferta hacia el frente marítimo, con una leve tendencia hacia la desconcentración, aunque la localización principal sigue siendo Ciutat Vella y el Eixample. En el primero de los dos distritos sigue habiendo una proporción elevada de establecimientos de menor categoría.

Finalmente, en quinto lugar, este crecimiento de la oferta y de la demanda va acompañado por tensiones en la ciudad. El turismo se ha convertido en un elemento claramente estructurador de la ciudad, puesto que su actividad incide de manera transversal en el conjunto de la sociedad barcelonesa y afecta a su vida económica, social, cultural y territorial en múltiples vertientes, ya que llegan todo tipo de visitantes que utilizan y viven la ciudad y sus entornos por motivos cada vez más plurales. Ello puede provocar que las molestias que experimentan algunos vecinos ayuden a generar en la opinión pública malestar y sentimientos en contra del turismo que acaben confluyendo y retroalimentando discursos contrarios a esta actividad.

Así pues, esta evolución, altamente positiva en lo cuantitativo (generación de producto, empleo y recaudación impositiva) y en lo cualitativo (marca internacional, atracción de inversiones), conlleva ciertas amenazas que si no son adecuadamente gestionadas pueden alterar esta tendencia. En este sentido, en este trabajo se han reseñado tres elementos que deberían ser adecuadamente gestionados y corregidos, principalmente: $a$ ) el aumento de la estacionalidad; b) la gran concentración de los flujos turísticos (y oferta) en un espacio muy reducido de la ciudad; $\mathrm{y} c$ ) las externalidades negativas que el crecimiento ha generado en un segmento de la ciudadanía. Tales amenazas deberían ser contrarrestadas con políticas de corrección de la estacionalidad (producto, mercados, 
precios), de desconcentración de la actividad y de gestión social del crecimiento turístico.

En definitiva, la ciudad, los gestores y los agentes no deben caer en la complacencia. Barcelona es un destino que aparece en el mapa turístico mundial desde hace pocos años y que necesita nuevas políticas que lo consoliden y hagan crecer de manera conveniente. No es el momento de laissez-faire laisser-passer sino el momento de la política pública en mayúsculas. Y esta política implica la participación social, un esquema al que, lamentablemente, todavía no estamos acostumbrados en este país.

\section{Referencias bibliográficas}

Ajuntament de Barcelona (2009). Pla estratègic de turisme de la ciutat de Barcelona. Barcelona: Ajuntament de Barcelona.

- (2014). Anuario Estadístico de la Ciudad de Barcelona 2014. Barcelona: Departament d'Estadística, Ajuntament de Barcelona.

Allcok, J. B. (1996). «Seasonality in Tourism». En: Moutinho, L. (eds.). Tourism and Marketing and Management Handbook. Nueva York: Prentice Hall, 86-92.

Andriotis, K. (2005). «Seasonality in Crete: Problem or a way of life?». Tourism Economics, 11 (2), 207-224. $<$ http://dx.doi.org/10.5367/0000000054183478>

Ashworth, G. y Page, S. (2011). «Urban tourism research: Recent progress and current paradoxes». Tourism Management, 32, 1-15. <http://dx.doi.org/10.1016/j.tourman.2010.02.002>

BARRADO, D. A. (2010). «Gran ciudad y turismo en la transición postindustrial: nuevos y viejos procesos, nuevas y viejas teorías. El ejemplo del área metropolitana de Madrid». Scripta Nova, vol. xIv, 317, 7-36.

Benach, N. (1993). «Producción de imagen en la Barcelona del 92». Estudios Geográficos, vol. LIV, 212, 483-505.

Benach, N. y Tello, R. (2004). «En los intersticios de la renovación. Estrategias de transformación del espacio y flujos de población en Barcelona». Revista de Geografia, 3, 93-114.

BorJa, J. (2010). Luces y sombras del urbanismo de Barcelona. Barcelona: UOC.

Bové, M. A. y Guim, M. (2013). La eclosión turística de Barcelona. Política de planificación vs cooperación público-privada. Documento de trabajo. $<$ http://www.reunionesdeestudiosregionales.org/Oviedo2013/htdocs/pdf/p717. pdf> (consulta: 12 de mayo de 2015)

Buhalis, D. (2000). «Marketing the competitive destination of the future». Tourism Management, 21 (1), 97-116. <http://dx.doi.org/10.1016/S0261-5177(99)00095-3>

Butler, R. y MaO, B. (1997). «Seasonality in tourism: Problems and measurement». En: Murphy, P. (eds.). Quality Management in Urban Tourism. Chichester: Wiley, 9-23.

CÀnoves, G. y GaraY, L. A. (2012). «Turismo de cruceros en Barcelona. De la marginalidad al liderazgo internacional». Boletín de la Asociación de Geógrafos Españoles, 60, 253-271.

Capel, H. (2010). «Epílogo. ¿En qué ha fallado Barcelona?». Finisterra, vol. xLv, 90, 173-204. 
Capó, J., Riera, A. y Rosselló, J. (2007). «Accommodation determinants of seasonal patterns». Annals of Tourism Research, 34 (2), 422-436. <http://dx.doi.org/10.1016/j.annals.2006.10.002>

Cardona, J. R. (2014). «La estacionalidad turística e sus potenciales impactos». Rosa dos Ventos, 6 (3), 446-468.

Cuccia, T. y Rizzo, I. (2011). "Tourism seasonality in cultural destinations: Empirical evidence from Sicily». Tourism Management, 32 (3), 589-595. <http://dx.doi.org/10.1016/j.tourman.2010.05.008>

Dachevsky, M. (2001). Urban Zapping. Ciudades, productos y marcas. Barcelona: Edicions de la UPC.

Duran, P. (2002). «Turisme: els impactes dels Jocs i de la seva imatge sobre el turisme». En: M. Moragas y M. Botella (dirs.). Barcelona: l'herència dels Jocs (19922002). Cerdanyola (Barcelona): UAB, Centre d'Estudis Olímpics, 275-294.

ELFAA (2004). Liberalisation of European air transport: The benefits of low fares airlines to consumers, airports, regions and the environment. Bruselas: European Low Fares Airline Association.

Euromonitor International (2014). Top 100 City Destinations Ranking. Londres. <http://blog.euromonitor.com/2014/01/euromonitor-internationals-top-citydestinations-ranking.html> (consulta: 12 de mayo de 2015)

European Cities Marketing (2014). The ECM Benchmarking Report. Dijon: ECM.

Garay, L. A. y CÀnoves, G. (2009). «El desarrollo turístico en Cataluña en los dos último siglos: Una perspectiva transversal». Documents d'Anàlsi Geogràfica, 53, $29-46$.

González, F. y Morales, S. (2009). Ciudades efímeras: transformando el turismo urbano a través de la producción de eventos. Barcelona: UOC.

Hedrick-Wong, Y. y Choong, D. (2014). 2014 Global Destination Cities Index. MasterCard. <http://newsroom.mastercard.com/wp-content/uploads/2014/07/Mastercard_ GDCI_2014_Letter_Final_70814.pdf> (consulta: 25 de mayo de 2015).

Hernández, J. A. (2008). «Turismo de masas y transporte: el gran reto del turismo del siglo XXI». Scripta Nova, vol. XII, 259.

Hinch, T. y Jackson, E. (2000). «Leisure constraints research: Its value as a framework for understanding tourism seasonality». Current Issues in Tourism, 3, 87-106. <http://dx.doi.org/10.1080/13683500008667868>

Hosteltur (2014). Informe anual 2013. Madrid: Hosteltur.

Institute for Urban Strategies. (2014). Global Power City Index 2014. The Mori Memorial Foundation.

<http://www.mori-m-foundation.or.jp/gpci/pdf/GPCI14_E_Web.pdf> (consulta: 25 de mayo de 2015).

JudD, D. R. (2003). «El turismo urbano y la geografía de la ciudad». Revista Eure, vol. Xxix, 87, 51-62. <http://dx.doi.org/10.4067/s0250-71612003008700004>

Koenig, N. y Bischoff, E. (2005). «Seasonality research: The state or the art». International Journal of Tourism Research, 7 (4/5), 201-219. $<$ http://dx.doi.org/10.1002/jtr.531>

López Palomeque, F. (1995). "La estrategia del turismo metropolitano: el caso de Barcelona». Estudios Turísticos, 126, 119-141.

Manning, R. y Powers, L. (1984). "Peak and Off-Peak use: Redistributing the Outdoor Recreation / Tourism Load». Journal of Travel Research, 23 (2), 25-31. <http://dx.doi.org/10.1177/004728758402300204> 
Mercado, S. (2000). Comercio Internacional I. México, DF: Limusa.

Mittal, V. y Kamakura, W. A. (2001). «Satisfaction, Repurchase Intent, and Repurchase Behavior: Investigating the Moderating Effect of Customer Characteristics». Journal of Marketing Research, 38, 131-142. <http://dx.doi.org/10.1509/jmkr.38.1.131.18832>

Murphy, P. E. (1985). Tourism: A Community Approach. Londres: Methuen.

NeL·LO, O. (2012). Ordenar el territorio. Valencia: Tirant lo Blanc.

Parker, C. y Mathews, B. P. (2001). "Customer Satisfaction: Contrasting Academic and Consumers' Interpretations». Marketing Intelligence \& Planning, 19 (1), 38-44. <http://dx.doi.org/10.1108/02634500110363790>

Pearce, D. G. (2001). «Urban tourism: an analytical framework for planning, management and research». En: Bao Jigang, Pan Ringlian y G. Wall (eds). Urban Tourism: theory and practice. Pekín: Science Press, 223-229.

Ponce, M. D. (2007). «Turismo de reuniones en la ciudad de Murcia. Un enfoque desde el tejido empresarial involucrado». Cuadernos de Turismo, 19, 105-131.

Prat, J. M. (2012). «El turismo industrial en la oferta cultural de las grandes ciudades a través del análisis de sus visitantes. El caso de Barcelona». Investigaciones Turisticas, 3, 83-104.

Puerto Autónomo de Barcelona (PAB) (1989). Plan Director. Manuscrito. Barcelona: PAB.

Richards, G. y Palmer, R. (2010). Eventful cities. Oxford: Elsevier.

Romero, J. (1990). «Els factors de localització hotelera a Barcelona, 1849-1989». Documents d'Anàlisi Geográfica, 16, 53-75.

Shoval, N., Mc Kercher, B. Erica, N.G. y Amit, B. (2011). "The geography of hotels in cities: an empirical validation of a forgotten model». Tourism Geographies, 8 (1), 56-75. <http://dx.doi.org/10.1080/14616680500392499>

Smith, A. (2012). Events and urban regeneration: the stategic use of events to revitalise cities. Londres: Routledge.

Stanciulescu, G. C. (2009). "The role of urban marketing in the local economic development». Theoretical and Empirical Researches in Urban Management, 1 (10), $114-135$.

Sutcliffe, C. y Sinclair, M. (1980). "The measurement of seasonality within the tourist industry: An application to tourist arrivals in Spain». Applied Economics, $12,429-441$. <http://dx.doi.org/10.1080/00036848000000004>

Toselli, C. (2006). «Algunas reflexiones sobre el turismo cultural». Pasos. Revista de Turismo y Patrimonio Cultural, 4 (2), 175-182.

Turisme de Barcelona (2015a). Estadísticas de turismo en Barcelona. Barcelona: Ajuntament de Barcelona. <http://professional.barcelonaturisme.com> (consulta: 12 de mayo de 2015)

- (2015b). Pla Estratègic de Turisme de la Ciutat de Barcelona. Barcelona: Ajuntament de Barcelona. <http://www.turismebcn2015.cat/T2015WEB/Que-es/_Sb46WFTR8WoXPZuwwMDEOQGZrnkYx3wBvvPkGi1xJis> (consulta: 25 de mayo de 2015).

- (1995). Memòria 1994. Barcelona: Ajuntament de Barcelona.

Vargas, A., Porras, N. y Plaza, M. (2014). «Residents' Attitude to Tourism and Seasonality». Journal of Travel Research, 53 (5), 581-596. <http://dx.doi.org/10.1177/0047287513506295> 
Velasco, M. (2009). "Gestión turística del patrimonio cultural: enfoques para un desarrollo sostenible del turismo cultural». Cuadernos de Turismo, 23, 237-253.

Vila, J. (1992). «La gran aventura de los Juegos Olímpicos de 1992 y el sector turístico de Barcelona». Revista de Estudios Turísticos, 113, 25-40.

Wahab, S. y Pigram, J. J. (eds.) (1997). Tourism, Development and Growth. Nueva York: Routledge.

YANG, Y., WonG, K. K. F. y WANG, T. (2012). «How do hotels choose their location? Evidence from hotels in Beijing». International Journal of Hospitality Management, 31 (3), 675-685.

$<$ http://dx.doi.org/10.1016/j.ijhm.2011.09.003> 